\title{
Contactless Manipulation of Soft Robots
}

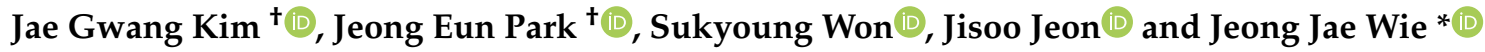 \\ Department of Polymer Science and Engineering, Inha University, Incheon 22212, Korea; \\ jkkim401@inha.edu (J.G.K.); 22171192@inha.edu (J.E.P.); sukyoung@inha.edu (S.W.); wjswltn0309@inha.edu (J.J.) \\ * Correspondence: wie@inha.ac.kr; Tel.: +82-32-860-7484 \\ + These authors contributed equally to this work.
}

Received: 27 August 2019; Accepted: 18 September 2019; Published: 20 September 2019

\begin{abstract}
In recent years, jointless soft robots have demonstrated various curvilinear motions unlike conventional robotic systems requiring complex mechanical joints and electrical design principles. The materials employed to construct soft robots are mainly programmable anisotropic polymeric materials to achieve contactless manipulation of miniaturized and lightweight soft robots through their anisotropic strain responsivity to external stimuli. Although reviews on soft actuators are extensive, those on untethered soft robots are scant. In this study, we focus on the recent progress in the manipulation of untethered soft robots upon receiving external stimuli such as magnetic fields, light, humidity, and organic solvents. For each external stimulus, we provide an overview of the working principles along with the characteristics of programmable anisotropic materials and polymeric composites used in soft robotic systems. In addition, potential applications for untethered soft robots are discussed based on the physicochemical properties of programmable anisotropic materials for the given external stimuli.
\end{abstract}

Keywords: soft robots; anisotropic materials; liquid crystalline polymers; magnetic composites; hydrogels

\section{Introduction}

Soft robots implement facile curvilinear motions and various functions including bending, twisting, and folding without employing numerous rigid joints. In particular, untethered soft robotic systems provide a high degree of freedom for motility by removing limitations of working distance and complexity of motion originating from distance and wire tangling, respectively. In the case of centimeter-scale or larger bulk soft robots, the pneumatic actuation mechanism is dominantly demonstrated through air pressure control. However, these pneumatic systems often utilize a tethered inlet and outlet of fluid, thus hampering miniaturization and limiting the degree of freedom for soft robotic motility. To achieve untethered manipulation of miniaturized soft robots, diverse anisotropic materials and composites have been investigated for stimuli-responsive motility using magnetic fields [1-11], light [12-27], organic solvents [28-38], and chemical reactions [39-43]. As representative anisotropic materials, liquid crystalline polymers can achieve contactless motility under external stimuli through programmable molecular orientations and resultant deformation. In particular, photoactive molecular machines that perform reversible molecular contraction and expansion by actinic light can be polymerized together with liquid crystalline monomers to produce photomotility [12-27]. Magnetic composites allow continuous and multimodal motility through programming particle alignment and/or the magnitude and direction of electromagnetic fields [1-11]. Moreover, hygromorphic materials and hydrogels can also show directed motility in response to chemical (solvent, water, and $\mathrm{pH}$ ) stimuli [28-38]. Recent research reports examples of soft actuators constructed from the aforementioned stimuli-responsive materials including polyelectrolyte and shape memory polymers [44-46]. In addition, reviews on anisotropic soft materials have been restricted to actuators or addressed tethered and 
untethered soft robotic systems [47-54]. As shown in Figure 1, the merits of anisotropic materials can be prominent as soft robots move toward small-scale contactless manipulation, as previously mentioned. Therefore, the aim of this study is to highlight recent reports and introduce the working principles for each material whereby external stimuli are converted into mechanical energy (Table 1). More specifically, the system using anisotropic magnetic particles and polymer composites is discussed in terms of robot geometry and particle alignment, and the various movements of liquid crystalline polymers and composites, which are representative examples of anisotropic molecules, are also considered in this work. Finally, we discuss the responsivity of soft robots to solvents, $\mathrm{pH}$, or chemical reactions, and we conclude by suggesting from an interdisciplinary perspective future research to overcome the remaining challenges.

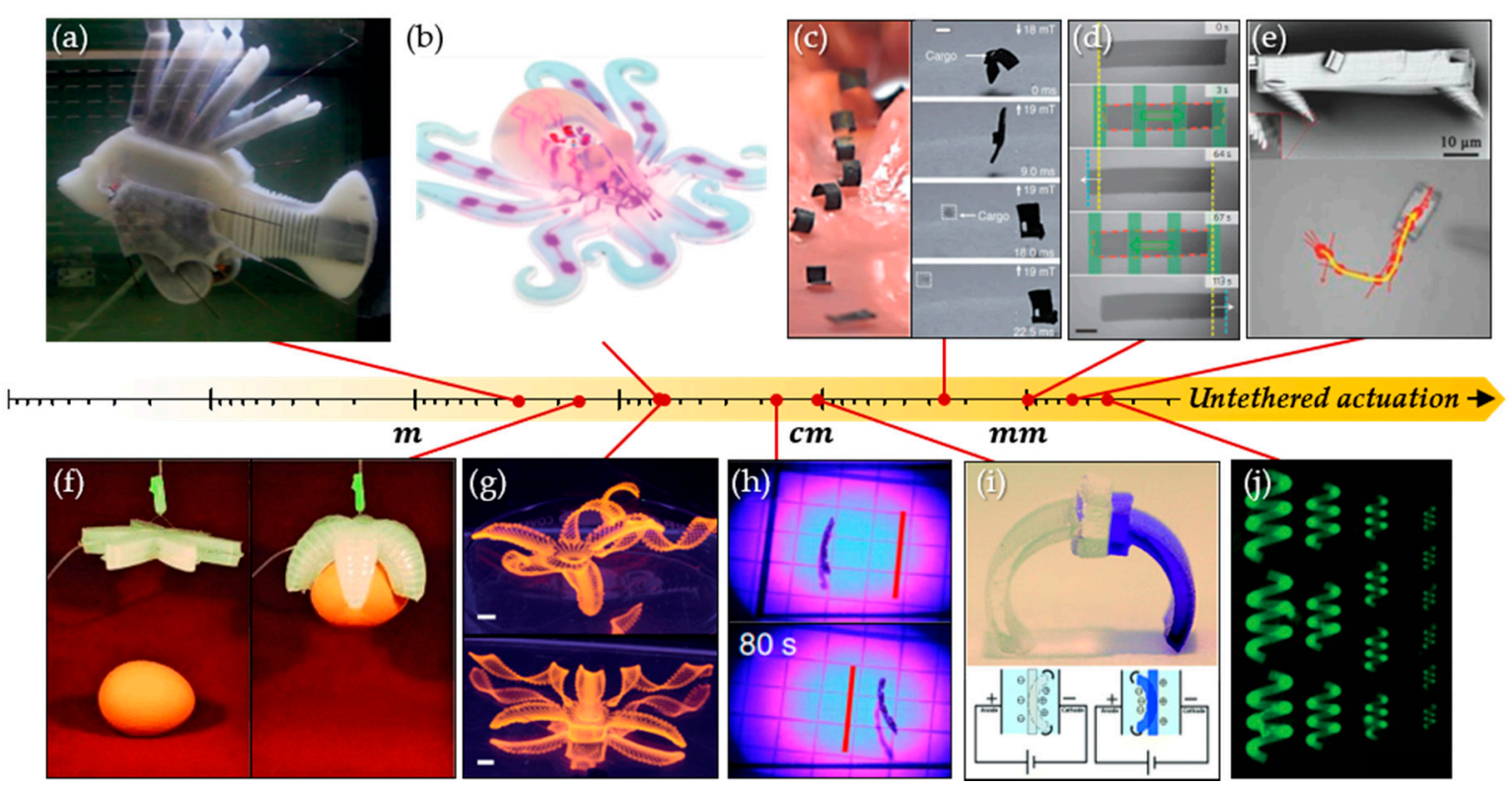

Figure 1. Soft robots (from meter to sub-mm). (a) Vascular-system-adapted swimming soft robot. (b) Chemical-reaction-fueled pneumatic octobot. (c) Multi-modal magnetic soft robot. (d) Underwater swimmer with a photoactive liquid crystal polymer. (e) Walking liquid crystal polymeric soft robot. (f) Pneumatic gripper. (g) Biomimetic three-dimensional (3D)-printed hydrogel flower. (h) Helical photomobile liquid crystal polymeric soft robot. (i) Electro-active walking soft robot. (j) Magnetic swimmer. (a) Reproduced with permission [55]. Copyright 2019, Nature Publishing Group. (b) Reproduced with permission [43]. Copyright 2016, Nature Publishing Group. (c) Reproduced with permission [9]. Copyright 2018, Nature Publishing Group. (d) Reproduced with permission [26]. Copyright 2016, Nature Publishing Group. (e) Reproduced with permission [19]. Copyright 2015, Wiley-VCH. (f) Reproduced with permission [56]. Copyright 2011, Wiley-VCH. (g) Reproduced with permission [30]. Copyright 2016, Nature Publishing Group. (i) Reproduced with permission [40]. Copyright 2014, Royal Society of Chemistry. (j) Reproduced with permission [57]. Copyright 2018, Wiley-VCH. 
Table 1. A brief summary of magnetic soft robots including motility, external environments, magnetic source for actuation, geometry, materials, fabrication method, advantages, and limitations.

\begin{tabular}{|c|c|c|c|c|c|c|c|}
\hline Categories & Motility & $\begin{array}{l}\text { Magnetic Source } \\
\text { for Actuation }\end{array}$ & Geometry & Materials & $\begin{array}{l}\text { Fabrication Method for } \\
\text { Geometry }\end{array}$ & Advantages & Limitations \\
\hline \multirow{4}{*}{$\begin{array}{l}\text { Programming } \\
\text { geometry of robots } \\
\text { for desired } \\
\text { actuation }\end{array}$} & \multirow[t]{2}{*}{ Swimming } & \multirow{2}{*}{$\begin{array}{l}\text { Rotating magnetic } \\
\text { field of Helmholtz } \\
\text { coil }\end{array}$} & \multirow{3}{*}{ Helical coil } & SU- 8 or IP-L and Ni/Ti & $\begin{array}{l}\text { DLW (dynamic light } \\
\text { writing) [1] }\end{array}$ & $\begin{array}{l}\text { High resolution morphology and } \\
\text { transportability of cargo using } \\
\text { carrier }\end{array}$ & \multirow[t]{2}{*}{$\begin{array}{l}\text { Fragile body of } \\
\text { matrix materials }\end{array}$} \\
\hline & & & & $\begin{array}{l}\text { S. Platensis and } \\
\text { magnetite }\end{array}$ & Dip coating [2] & $\begin{array}{c}\text { Biocompatibility, } \\
\text { biodegradability, and MR } \\
\text { imaging functionality }\end{array}$ & \\
\hline & Rolling & \multirow{2}{*}{$\begin{array}{l}\text { Linearly applied } \\
\text { magnetic field of } \\
\text { permanent } \\
\text { magnets }\end{array}$} & & \multirow{2}{*}{$\begin{array}{c}\text { PDMS } \\
\text { (polydimethylsiloxane) } \\
\text { and iron } \\
\text { microparticles }\end{array}$} & $\begin{array}{l}\text { Wrapping precured film } \\
\text { around sticks [7] }\end{array}$ & $\begin{array}{l}\text { Facile fabrication method, linear } \\
\text { motility despite of helix geometry } \\
\text { and climbing uphill and discrete } \\
\text { walls }\end{array}$ & \multirow[t]{2}{*}{$\begin{array}{l}\text { Difficult control of } \\
\text { precise locomotion } \\
\text { directions }\end{array}$} \\
\hline & Crawling & & $\begin{array}{l}\text { Multi-legs } \\
\text { with body }\end{array}$ & & $\begin{array}{l}\text { Assembly of uncured } \\
\text { composite resin [6] }\end{array}$ & $\begin{array}{l}\text { Facile fabrication method, fast } \\
\text { locomotion speed, loading cargo } \\
\text { and climbing uphill }\end{array}$ & \\
\hline \multirow{3}{*}{$\begin{array}{l}\text { Programming } \\
\text { alignments of } \\
\text { magnetic } \\
\text { components for } \\
\text { single-modal } \\
\text { actuation }\end{array}$} & Crawling & $\begin{array}{l}\text { Linearly applied } \\
\text { magnetic field of } \\
\text { Helmholtz coil }\end{array}$ & \multirow[t]{2}{*}{ Head and tail } & $\begin{array}{l}\text { PEGDA (poly } \\
\text { ethylene glycol } \\
\text { diacrylate) and silicon } \\
\text { coated magnetite }\end{array}$ & $\begin{array}{l}\text { SLM (spatial light } \\
\text { modulator) with aligning } \\
\text { of magnetic particles by } \\
\text { permanent magnets [5] }\end{array}$ & $\begin{array}{l}\text { Uncomplicated control of } \\
\text { locomotion directions } \\
\text { (forward/backward) }\end{array}$ & $\begin{array}{l}\text { Multiple } \\
\text { manipulation } \\
\text { steps of magnetic } \\
\text { field for one } \\
\text { motion }\end{array}$ \\
\hline & Swimming & \multirow[t]{2}{*}{$\begin{array}{l}\text { Rotating magnetic } \\
\text { field of Helmholtz } \\
\text { coil }\end{array}$} & & $\begin{array}{l}\text { PEGDA (poly ethylene } \\
\text { glycol diacrylate), } \\
\text { PNIPAM (poly } \\
\text { N-isopropylacrylamide) } \\
\text { and magnetite }\end{array}$ & $\begin{array}{c}\text { Lithography with } \\
\text { alignment of magnetic } \\
\text { particles by solenoid coil } \\
\text { and folding/defolding of } \\
\text { body by temperature } \\
\text { variation [4] }\end{array}$ & $\begin{array}{l}\text { Multiple stimuli responses and } \\
\text { reversible shape morphing }\end{array}$ & $\begin{array}{l}\text { Complicated } \\
\text { fabrication steps }\end{array}$ \\
\hline & Tumbling & & Bridged body & $\begin{array}{l}\text { SU-8 and NdFeB } \\
\text { (neodymium) } \\
\text { microparticles }\end{array}$ & $\begin{array}{c}\text { Lithography with } \\
\text { alignments of magnetic } \\
\text { particles by permanent } \\
\text { magnets [8] }\end{array}$ & $\begin{array}{l}\text { Climbing uphill and steerability } \\
\text { to desired positions }\end{array}$ & $\begin{array}{l}\text { Fragile body of } \\
\text { matrix materials }\end{array}$ \\
\hline \multirow{2}{*}{$\begin{array}{l}\text { Programming } \\
\text { polarity of } \\
\text { magnetic } \\
\text { components for } \\
\text { multi-modal } \\
\text { actuation }\end{array}$} & $\begin{array}{l}\text { Multimodality } \\
\text { (swimming, } \\
\text { climbing, rolling, } \\
\text { walking, jumping, } \\
\text { crawling) }\end{array}$ & $\begin{array}{l}\text { Linearly applied } \\
\text { magnetic field of } \\
\text { electromagnets } \\
\text { and Helmholtz coil }\end{array}$ & Film & $\begin{array}{l}\text { Ecoflex and NdFeB } \\
\text { (neodymium) } \\
\text { microparticles }\end{array}$ & $\begin{array}{l}\text { Wrapping precured film } \\
\text { around sticks and aligning } \\
\text { of particle polarity by } \\
\text { electromagnets [9] }\end{array}$ & $\begin{array}{l}\text { Multimodal locomotion of a } \\
\text { single body, transportability of } \\
\text { cargo, and steerability to desired } \\
\text { positions with precise regulation }\end{array}$ & \multirow{2}{*}{$\begin{array}{l}\text { Difficulty of } \\
\text { remaining desired } \\
\text { geometry without } \\
\text { magnetic field }\end{array}$} \\
\hline & $\begin{array}{l}\text { Rolling/crawling } \\
\text { /jumping }\end{array}$ & $\begin{array}{l}\text { Linearly applied } \\
\text { magnetic field of } \\
\text { Helmholtz coil }\end{array}$ & $\begin{array}{l}\text { Diverse } \\
\text { structures (e.g., } \\
\text { hexapedal } \\
\text { body) }\end{array}$ & $\begin{array}{l}\text { Ecoflex, PDMS and } \\
\text { NdFeB (neodymium) } \\
\text { microparticles }\end{array}$ & $\begin{array}{c}\text { Inkjet printing and } \\
\text { alignment of particle } \\
\text { polarity by } \\
\text { electromagnets [10] }\end{array}$ & $\begin{array}{l}\text { Facile alignment process along } \\
\text { printing directions, construction } \\
\text { of diverse hierarchical } \\
\text { three-dimensional structures }\end{array}$ & \\
\hline
\end{tabular}




\section{Magnetic Soft Robots}

Magnetic actuation has been significantly considered in battery-free systems and blocked environments because of the penetrable feature of a magnetic field. An external magnetic stimulus manipulates the locomotion of soft robots with a fast response and endows a powerful functional tool for actuation without setting the atmospheric pressure, temperature, solvent, or $\mathrm{pH}$ conditions.

In addition, its non-destructive property is also advantageous to extend soft robotic applications to biomedical technologies for drug delivery, diagnosis, and non-surgical therapy.

Diverse modes of magnetomotility have been reported, including swimming [1,2,4], crawling [5,6], rolling [7], tumbling [8], and multimodal motilities [9,10]. Motile strategies to achieve magnetic maneuvers have been widely developed by programming (i) the geometry of robots, (ii) the positional alignments of magnetic components, and (iii) the polarity of the magnetic domain of magnetic components. With respect to magnetic materials, the driving force of motility is a magnetic torque to match the magnetic alignments or polarity in the direction of the magnetic field. Positional alignments can be induced by a relatively weak magnetic field of permanent magnets ( $\mathrm{a}$ few hundreds of $\mathrm{mT}$ ) or a solenoid coil such as a Helmholtz coil (a few tens of mT). However, programming polarity requires strong electromagnetic devices $(\mathrm{a}$ few $\mathrm{T}$ ) that have an iron core wrapped in wire. In addition to preparing magnetic soft robots, the Helmholtz coil system has the advantage of simultaneous control of three axes to manipulate the magneto-motility of soft robots. In the case of programmed magnetic polarity, selective control can achieve multimodal motility. However, in a permanent setup, precisely changing the magnetic direction is more difficult. By contrast, the Helmholtz coil system restricts the moving distances of soft robots because of the constrained space of the device, unlike permanent magnets.

The magnetic characteristics of magnetic materials are also major factors for on-demand magnetic actuation. Magnetism is generally categorized into diamagnetism, paramagnetism, ferromagnetism, and ferrimagnetism based on the variation in dipole moments under an external magnetic field. Diamagnetic materials have oppositely aligned dipole moments to the direction of the magnetic field, although the dipole moments vanish in the absence of a magnetic field. Paramagnetic materials have aligned dipole moments in the direction of the magnetic field. Then, they are varied to randomized alignments without a magnetic field. Finally, ferromagnetic materials have aligned dipole moments in the direction of the magnetic field, which are retained even when the magnetic field is removed [10]. Ferrimagnetic materials have a similar property of ferromagnetism except that they contain diamagnetic elements such as oxygen, which results in reduced magnetization.

The ferro- and ferri-magnetic particles are divided into two types, soft and hard magnets, using a criterion of magnetic coercivity (Figure 2). According to the International Electrotechnical Commission Standard 404-1, the coercivity $\left(\mathrm{H}_{\mathrm{c}}\right)$ of soft magnets is less than $1000 \mathrm{~A} / \mathrm{m}$, whereas that of hard magnets is greater than $100,000 \mathrm{~A} / \mathrm{m}$ [58]. The residual magnetization $\left(\mathrm{M}_{\mathrm{r}}\right)$ of hard magnets is relatively higher than that of soft magnets, leading to the tunability of dipole moments via electromagnetic devices. In addition, a superparamagnetic feature appears in ferro- and ferri-magnetic particles [59]. The coercivity and remanence are zero when the particle diameter decreases to $10-20 \mathrm{~nm}$. Thermal fluctuation causes the magnetic moment to flip because the thermal energy is higher than the energy barrier for magnetization. Superparamagnetism appears in the randomized direction of the magnetization vector in the absence of an external magnetic field. Superparamagnetic particles do not retain magnetization in the absence of a magnetic field, decreasing the probability of aggregation. In the field of soft robotics, superparamagnetic magnetite is utilized to accomplish magnetic actuation without magneto-hysteresis. 


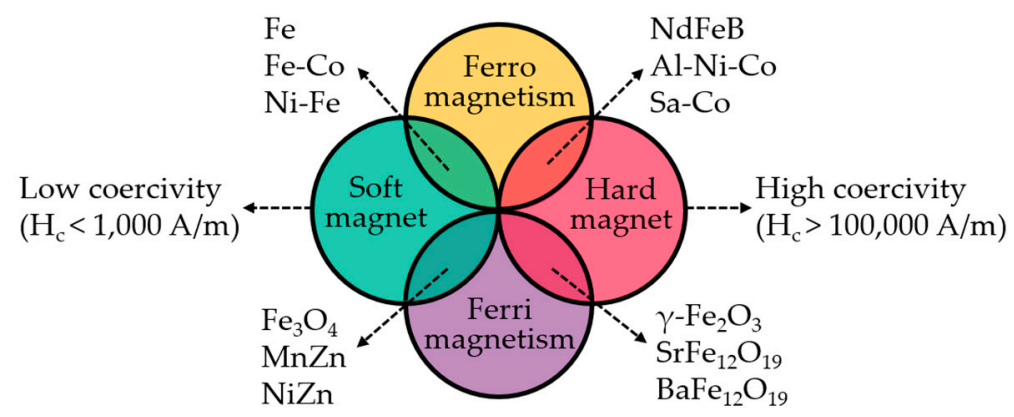

Figure 2. Classification of magnetic materials.

Modifying magnetic particles can be a strategy to enhance magnetic response. A combination of magnetic particles generates a synergistic effect such as enhancements of storage modulus in aspects of magnetorheological properties [60-64]. Exchange coupling leads to reduced saturated magnetization $\left(\mathrm{M}_{\mathrm{S}}\right)$ and enhanced coercivity $\left(\mathrm{H}_{\mathrm{c}}\right)$. Composite particles dispersed in a polymer matrix can be an alternative to producing a higher magneto-response under a lower magnetic field in the field of magnetically active soft robots.

\subsection{Programming Geometry of Robots for Desired Actuation}

Helical geometry has been mainly reported to achieve 3D swimming in liquid environments inspired by bacterial flagella $[1-3,11]$. The rotational motion of the helical robots was converted to linear translational motion such as a corkscrew motion, which is an effective strategy for propulsion at a low Reynolds number. The helical 3D structure can be prepared using a top-down approach such as dynamic light writing (DLW) [1]. A helical geometry was fabricated using a SU-8 or IP-L, followed by a coating of an Ni/Ti bilayer (Figure 3(ai)). SU-8 polymer is a commonly used epoxy-based negative photoresist material. The helix angle is crucial in achieving corkscrew motion and reducing wobbling from the rotational axis at the high frequency of a magnetic field (Figure 3(aii)). Transportation functionality of a micro holder was demonstrated by loading and releasing polystyrene particles with a diameter of $6 \mu \mathrm{m}$. A microparticle was loaded by the fluidic drag force against a swimming motion and released by reversed swimming backward. The capability of transportation implies the potential of biomedical applications including cancer therapy with localized drug delivery.

Dip-coating of magnetite $\left(\mathrm{Fe}_{3} \mathrm{O}_{4}\right)$ was conducted on the helical frame of Spirulina platensis bacteria to readily prepare 3D swimming soft robots [2]. In addition, a biohybrid composition is aimed at biodegradability in medical applications. Coated magnetite suspension endowed not only magnetic responsivity but also magneto resonance (MR) contrasts. Because of the coating thickness, biodegradability was investigated by varying the morphology at $37^{\circ} \mathrm{C}$ incubation based on the temporal condition of dipping. In addition, the navigation performance was demonstrated through an in vivo test in rodent stomachs. MR imaging was achieved because of the innate bacterial fluorescence properties. However, cessation of imaging in the deep organs remained a challenging issue. A Helmholtz coil system has limited penetration of a magnetic field induced by the low magnitude of the magnetic field despite the advantage of three axes of precise control in the magnetic field.

The rolling motility of the helical geometry was easily controlled through linear translational movements of the permanent magnets in dry environments [7]. Helical geometry is an effective means of reducing rolling resistance because of its lower mass, particularly when compared to the higher mass of cylindrical geometry. A 3D helical structure was fabricated using the following two-step process: a polymeric composite was formed by mixing soft magnetic iron particles (Fe) and polydimethylsiloxane (PDMS) and then molded to a pre-cured film (Figure 3b). PDMS is an optically clear and non-toxic thermoset elastomer whose liquid resin is commonly used for molding. Helix construction is crucial because the rolling motility of 3D helical soft robots can accomplish novel tasks such as uphill climbing even under a low magnetic flux density of $110 \mathrm{mT}$ (Figure 3(bii)), 
whereas a two-dimensional (2D) composite film is only capable of being dragged using sliding resistance. Climbing was also demonstrated on discrete walls up to one-third the diameter of the body (Figure 3(biii)). The motion angle is parallel to the helix angle in the helical geometry, as reported by Wie et al., with light-induced rolling of helical azobenzene-functionalized liquid crystalline polymer networks (azo-LCNs) [14]. When magnetic momentum exceeds the rolling resistance and inertia, the rolling motility of magnetic soft robots emerges. Using permanent magnets, Park et al. achieved linear translational motility of helical magnetic composites by varying the magnetic velocity and magnetic flux density.
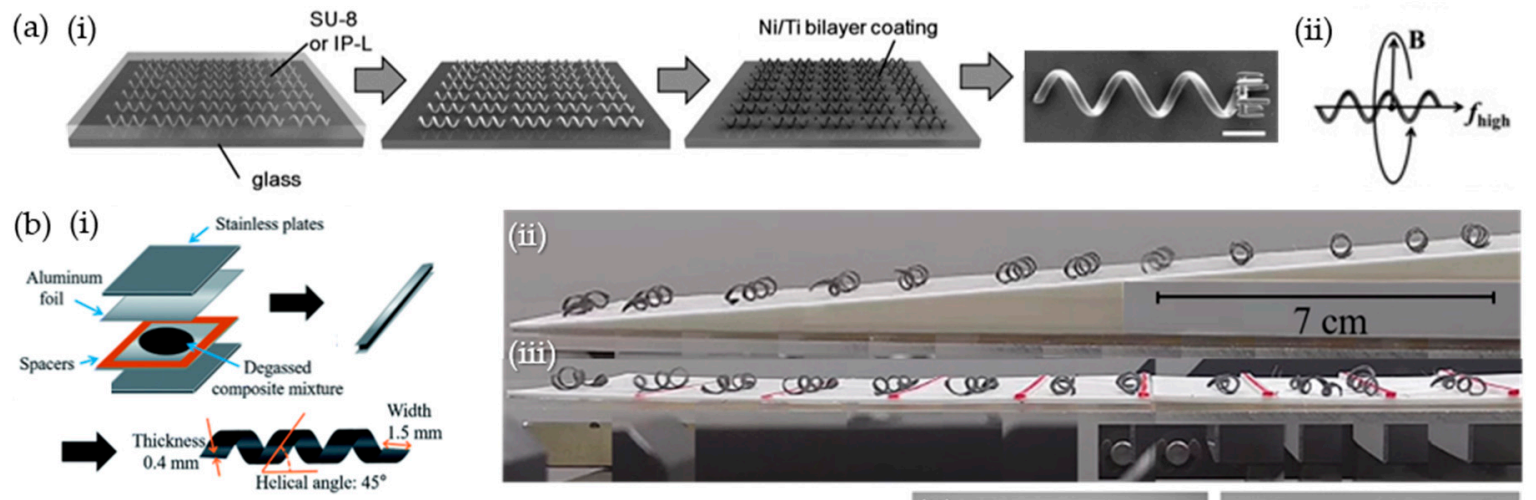

(c) (i)
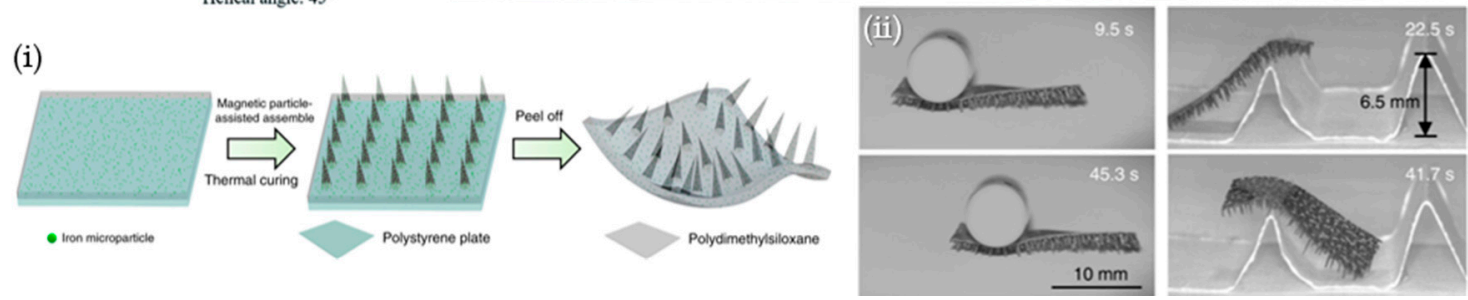

Figure 3. Geometry-induced locomotion of magnetic soft robots. (a) Helical soft robots produced using the dynamic light writing process when a photoresist polymer is used, followed by Ni/Ti bilayer coating: (i) scanning electron microscopy (SEM) image of helical micromachines with a microholder (scale bar: $10 \mu \mathrm{m}$ ), and (ii) principle of corkscrew motion. (b) Fabrication scheme for molding a helical geometry via (i) two-step polymerization, and (ii) ascending performance on uphill obstacles, and (iii) discrete walls. (c) (i) Preparation of multi-legged soft robots, (ii) loading performance at 100 times its own weight and when overcoming an obstacle. (a) was reproduced with permission [1]. Copyright 2012, Wiley-VCH.

The crawling motility of a multi-legged geometry solved a challenging issue regarding adaptability under wet and dry conditions, using 3-DoFs manipulator to control the position of permanent magnets. The leg geometry was prepared by the assembly phenomenon of magnetic polymeric composites along a magnetic flux (Figure 3c) [6]. Inspired by living organisms, the multi-legged geometry accomplished an ultrafast locomotion speed greater than $40 \mathrm{limb}$ lengths/s. The legs reduced the friction force on the dry ground and effectively lifted the body. Soft robots move not only in an upward and downward direction but also in a left to right direction by a programmed external magnetic field. Individually different movements of each leg induce complicated movements. The flexible property of the body is advantageous to load objects up to 100 times its own weight (Figure 3(cii)). Furthermore, soft robots can cross a steep obstacle greater than 10 times their body height by standing erect at $90^{\circ}$.

\subsection{Programming Alignments of Magnetic Components for Single-Modal Actuation}

Programming spatial alignments of a magnetic component leads to selective locomotion in parts and the preparation of 3D robot geometry. Magnetic particles including magnetite $\left(\mathrm{Fe}_{3} \mathrm{O}_{4}\right)$ or neodymium particle $(\mathrm{NdFeB})$ are aligned like a chain in a liquid resin along the external magnetic field to minimize magnetic dipole interaction energy. If the aligned particles are solidified in polymer 
matrices, the chain-like particles move toward the external magnetic field and induce actuation of the entire structure. An ultraviolet (UV)-curable hydrogel or a photoresist polymer were utilized for matrices such as poly (N-isopropylacrylamide) (PNIPAM) and poly (ethylene glycol diacrylate) (PEGDA) or SU-8. PEGDA and PNIPAM are commonly used hydrogels favored for their low toxicity. Light-induced crosslinking is essential to delicately and selectively program magneto-alignments within polymer matrices. Prepolymer states of composites require a rapid process time and strong intensity of light for photo-polymerization to avoid magnetic particle agglomeration.

Crawling motility was achieved by sequential locomotion through partially different alignments of segments inducing an arching motion and forward movements (Figure 4(ai,aii)) [5]. Superparamagnetic magnetite particles were aligned along the magnetic flux produced by permanent magnets as horizontal (bodies) and vertical (head and tail) alignments. Then, spatially resolved selective curing was implemented using a spatial light modulator (SLM) as the computational process. When the magnetic field was applied toward the upper right side, the tail of the soft robots was dragged forward. The magnetic field was changed to an upright direction and the two body sectors in the middle were deformed to an arch-like structure to arrange magnetic components parallel to the external magnetic field. Then, the upper left magnetic field induced forward head movement (i.e., a crawling motion). Swimming motility was also demonstrated through programming alignments of magnetic components by Nelson et al. Soft micromachines had orthogonal alignments of magnetite particles, namely, particles out-of-plane (supporting layer, upper part) and in-plane (responsive layer, lower part) (Figure 4(bi)) [4]. The programmed film was folded to form a tube-like geometry through the swelling properties of the hydrogel polymer, resulting in radial alignments of magnetic particles. Corkscrew-like rotating actuation was performed by radial alignment under a rotating magnetic field of $10 \mathrm{mT}$. In addition, aligned magnetite particles in the supporting layer also acted as reinforcing additives for a stiffness gradient. The folding axis of the tube was determined by the perpendicular direction of the aligned axis. Thermal conditions induced the folding and refolding phenomenon. This is because hydrogels swell below the low critical solution temperature (LCST) and shrink above the LCST (i.e., $\sim 32^{\circ} \mathrm{C}$ for PNIPAM) [65]. The swelling was also controlled for preferential folding toward a non-swelling PEGDA supporting layer against the swelling response of the PNIPAM layer. A helical tail was prepared by a folding mechanism perpendicular to the diagonal alignments and was compared to a planar tail to evaluate the swimming performance (Figure 4(bii)). The planar flagellum was shown to be propelled three times faster than the helical tail. This study illustrates the importance of stiffness gradients for the self-folding of 2D film. Furthermore, investigation of the curvy geometry suggests a strategy to develop the complicated geometry of soft robots. 
(a) (i)
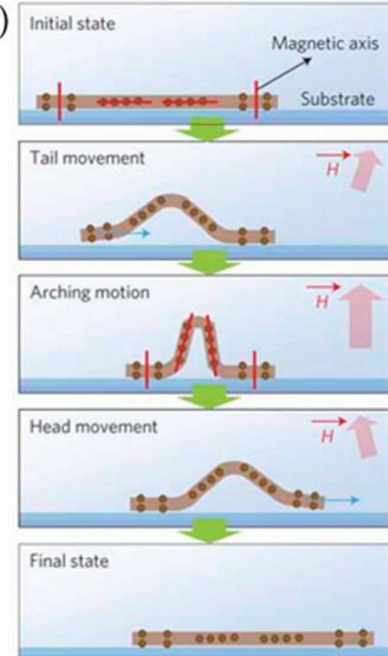

(ii)
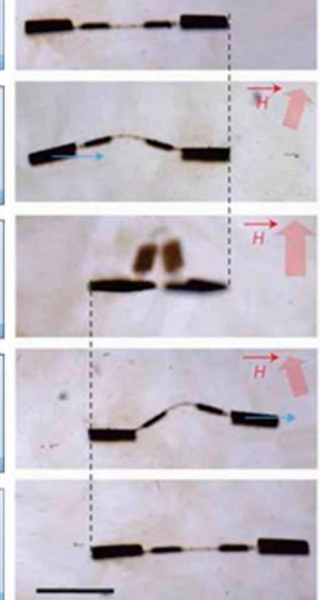

(b) (i)
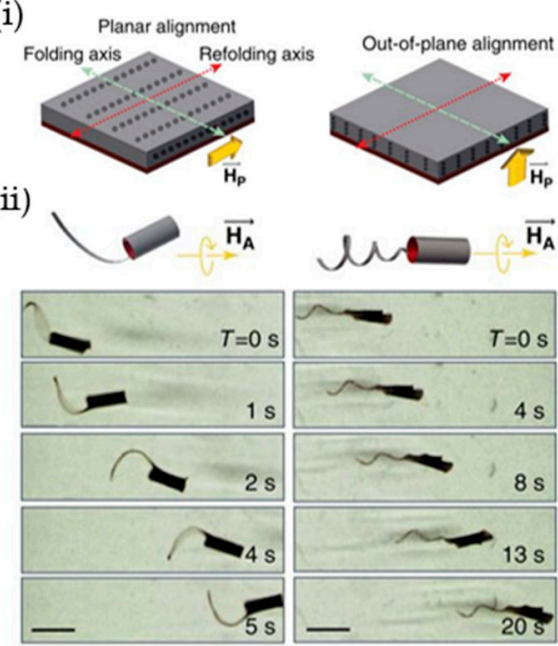

(c) (i)

(ii)

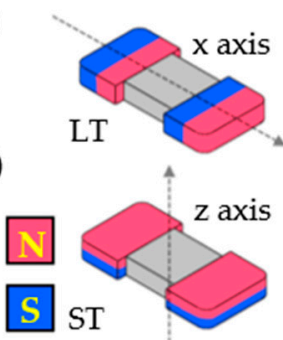

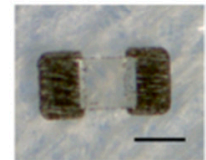

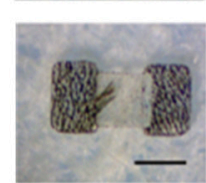

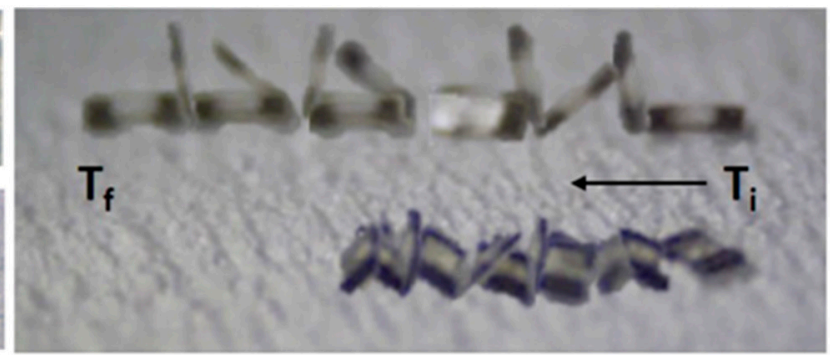

Figure 4. Directional motion induced by aligning magnetic components within a UV-curable polymer of soft robots. (a) (i) Schematic depiction of crawling motion, and (ii) optical snapshot images, including differently programmed head, tail (vertical alignments), and bodies (horizontal alignments) (scale bar: $100 \mu \mathrm{m}$ ). (b) (i) Preparation strategies for folding of a bilayer hydrogel film including two orthogonal magneto-alignments, and (ii) a time-lapse image of its swimming motility (scale bar: $2 \mathrm{~mm}$ ). (c) (i) Tumbling locomotion of axial alignments of the x-axis, and (ii) z-axis for lengthwise tumbling (LT) and sideways tumbling (ST), respectively (scale bar: $300 \mu \mathrm{m}$ ). (a) Reproduced with permission [5]. Copyright 2011, Nature Publishing Group.

Tumbling locomotion was devised by the morphology of segments of the polymeric composite body and magnetically inert polymer bridge. Polymeric composites of SU-8 and neodymium particles had positional alignments for magneto-motility [8]. The $\mathrm{x}$ and $\mathrm{z}$ axes were aligned and aimed for lengthwise tumbling (LT) (i) and sideways tumbling (ST) (ii) (Figure 4c). Hard magnetic particles had a merit of effective locomotion induced by a higher magnetization value at a lower magnetic flux density as compared to that of the soft magnetic particles. Initially, the middle bridge section was cured with a photomask, and then the composites were cast to both sides. The UV-curing process followed with a programming alignment of magnetic components using permanent magnets. Tumbling modes were demonstrated on rough substrates and inclined surfaces of $0^{\circ}-60^{\circ}$. Although the geometry was constrained to a rectangle, the tumbling motility could achieve complex navigation including even a curvy route. The remaining problems were to minimize slip with substrates and hooking action on sharp corners during a curvy maneuver.

\subsection{Programming Polarity of Magnetic Components for Multi-Modal Actuation}

Alignment of magnetic dipole moments suggests a remarkable approach for multimodal locomotion under a low external magnetic field by programming the magnetization profile of hard magnetic materials based on high remanence characteristics. Magnetic moments of atoms in hard magnetic particles such as neodymium $(\mathrm{NdFeB})$ microparticles are highly aligned under a few $\mathrm{T}$ of a magnetic field because the hard magnets feature high coercivity. However, magnetized hard 
magnetic particles yield magnetic polar directions after an external magnetic field is removed because of the high residual hysteresis. Tens of $\mathrm{mT}$ of a magnetic field are required to actuate magnetic soft robots compared to those composed of soft magnetic materials. The direction of the magnetic dipole moments is programmed when the magnetic particles are confined in cured polymer matrices, whereas the particle alignments are sequentially accompanied by rapid photopolymerization and masking techniques to prevent particle agglomeration in the prepolymer. Different polar directions within the soft robots cause partial deformation and actuation when the magnitude and directions of the applied magnetic field are varied.

Sitti et al. reported the following six locomotive modes from a single rectangular film as a strategy for controlling soft robots in diverse terrains: swimming, climbing, rolling, walking, jumping, and crawling [9]. A soft body was prepared using polymer composites of thermo-cured resin (Ecoflex10) and neodymium microparticles. Ecoflex has low density $\left(1.04 \mathrm{~g} / \mathrm{cm}^{3}\right)$ and is easy to handle for molding techniques. When the composite film was wrapped around a cylindrical stick, particles were magnetized with a counterclockwise polarity under a horizontal magnetic field of $1.7 \mathrm{~T}$. The curvature of the soft robot was sensitively manipulated based on the magnitude and direction of the magnetic field through the electromagnet. Deflection of sine, cosine, $C$, and V shapes could be achieved under a magnetic field of less than $20 \mathrm{mT}$ (Figure 5(ai)). Meniscus climbing, landing, and swimming modes in water can be transited into rolling, walking, crawling, and jumping motions in land environments. The multimodal locomotion facilitates navigation across a surgical stomach phantom and cargo transportation (Figure 5(aii)).

(a) (i)

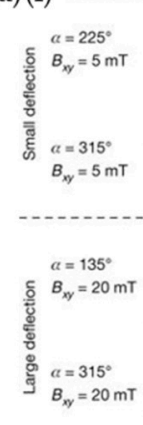

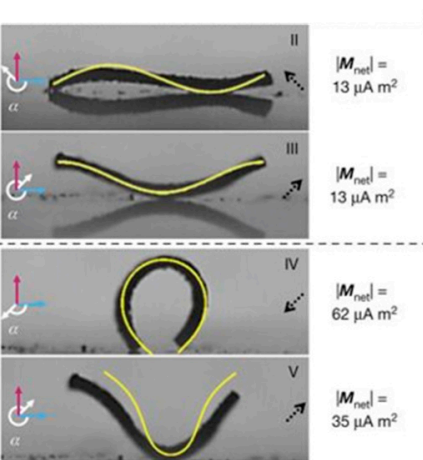

(ii)

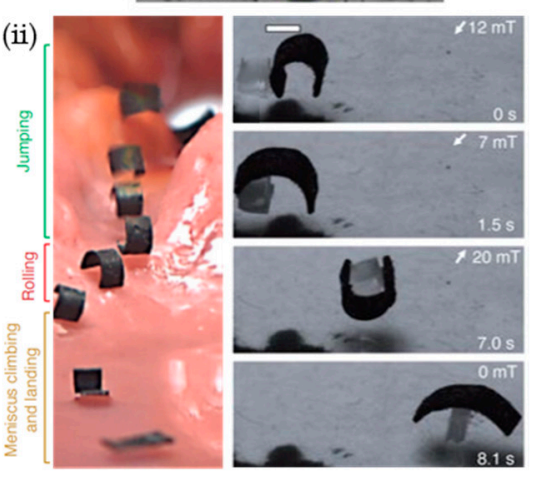

(b) (i)
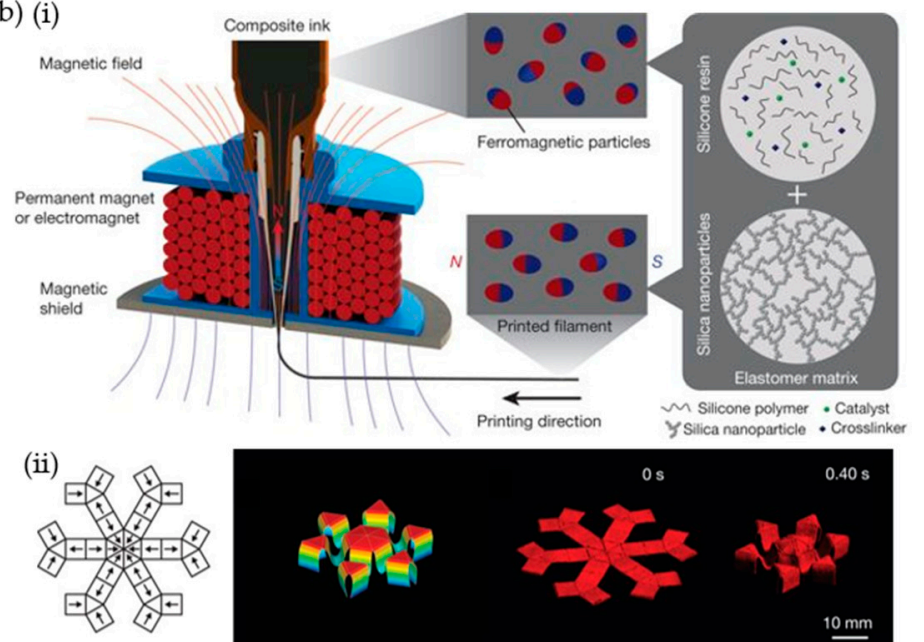
Stica nanoparticle $\bullet$ Crossinin

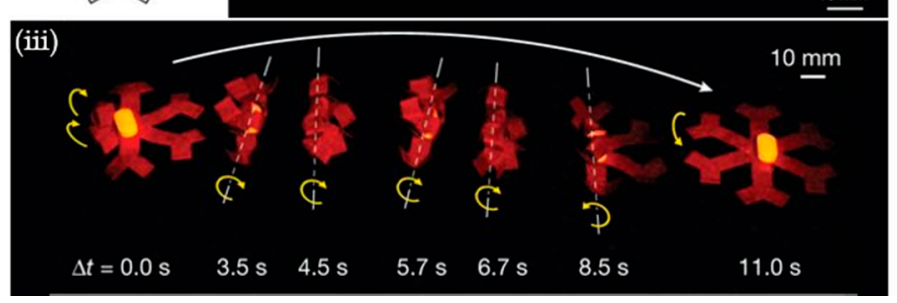

Figure 5. Multimodal magneto-actuation through multiple magneto-alignments in single soft robots. (a) (i) Reconfigurable soft body embedded with a counterclockwise alignment of polarity. (ii) Navigation across a synthetic stomach phantom and cargo transportation through multimodal locomotion (scale bars: $1 \mathrm{~mm}$ ). (b) (i) 3D printing process using composite inks composed of uniaxial reoriented magnetic particles under a magnetic field. (ii) Printing design of magnetic polarity with a top-down view and actuation of the printed hexapedal and auxetic structure. The height of the auxetic 3D structure is $5 \mathrm{~mm}$ at the bottom of the panel. (iii) Carrying a pharmaceutical pill with a six-legged structure. (a) was used with permission [9]. Copyright 2018, Nature Publishing Group. (b) Reproduced with permission [10]. Copyright 2018, Nature Publishing Group. 
Zhao et al. reported programmable multidirectional polarity for 2D and 3D structures by 3D printing composite inks [10]. The composite ink was composed of neodymium microparticles and silica nanoparticles dispersed in elastomer blends (SE1700 and Ecoflex30) and magnetized under 2.7 T. SE1700-grade silicone resin and silica nanoparticles were adopted for appropriate viscosity for 3D printing instead of Sylgard184-grade resin generally employed in the field of soft robots. The hard magnets were reoriented along the parallel direction of the flowing ink under a magnetic field of $50 \mathrm{mT}$ at the tip using permanent magnets or electromagnets (Figure 5(bi)). Polarity morphing was readily imparted because the polar direction formed along the printing direction. The hexapedal 2D structure was folded under a perpendicular magnetic field at $200 \mathrm{mT}$. In addition, shrinkage with a negative Poisson's ratio in the 3D auxetic structure was generated under the parallel direction of the magnetic field at $200 \mathrm{mT}$ (Figure 5(bii)). Because of the aligned magnetic moments, the transportable functionality of holding and carrying objects was achieved through a simple rotation of a permanent magnet (Figure 5(biii)).

\section{Liquid Crystalline Polymers}

Liquid crystal materials present a unique phase behavior between a conventional solid and liquid because of their electrical and geometrical anisotropic characteristics such as a rod-like or discotic molecular structure, strong dipoles, and/or easily polarizable substituents. Liquid crystal polymer networks are synthesized by crosslinking reactive-mesogenic monomers and by maintaining the ordered structure of the anisotropic liquid crystal phase. In particular, crosslinked liquid crystal polymers have a wide range of moduli from approximately $0.1-5 \mathrm{MPa}$ (low crosslink density liquid crystal elastomer; LCE) to 1-2 GPa (densely crosslinked liquid crystal network; LCN). In a nematic liquid crystalline polymer, the orientational order acts as an external body stress leading to elastic strain, whereas mechanical strain acts as an external field that aligns the mesogenic molecules [23]. Thus, a reduction in the degree of orientational order causes a mechanical strain of approximately $5 \%$ (LCN) to $90 \%$ (LCE) change upon heating. In general, photoisomerization of the dissolved dye [66] and thermal heating [67] scatter the molecules into a randomly oriented state in a liquid crystalline polymeric system. Upon heating, liquid crystal polymers undergo a nematic-paranematic [68] isotropic [69] phase transition, converting the material from an ordered to a disordered state. In light-responsive systems such as azobenzene-doped liquid crystal polymers, the order-disorder transition can be induced by breaking the molecular alignment via trans-cis photoisomerization of azobenzene moieties.

As a result of the decreased degree of order through external stimuli, the material undergoes shape morphing (contraction and expansion) in which the specific geometry of the deformation is determined by the distribution of the orientational direction within the material (Figure 6a). Thus, various physical approaches have been used to pattern the material structure and molecular alignment and obtain diverse and complex deformation/actuation modes. As shown in Figure $6 \mathrm{~b}$, the flat film bends into diverse shapes as a variety of molecular orientations across the film thickness [54]. Figure 6(ci) shows the actuation modes when the molecular alignments in the liquid crystalline polymers are varied [70]. As an example, the planar-to-homeotropic aligned molecules lead to complex forms of the film, which results in fingerprint-like shapes (Figure 6(cii)) [71]. This dynamic fingerprint-like surface can control the morphology under UV exposure and also modulate the friction. Furthermore, a complicated pattern of molecular distribution is needed for the 3D complex deformation. 3D printing [72-74] and lithography $[75,76]$ are examples of technologies developed to create 3D polymer structures with sophisticated control over deformation. Moving beyond simple, light-driven motion of soft robots, the main difficulty is how to generate and regulate multiple shapes in a single robot. 


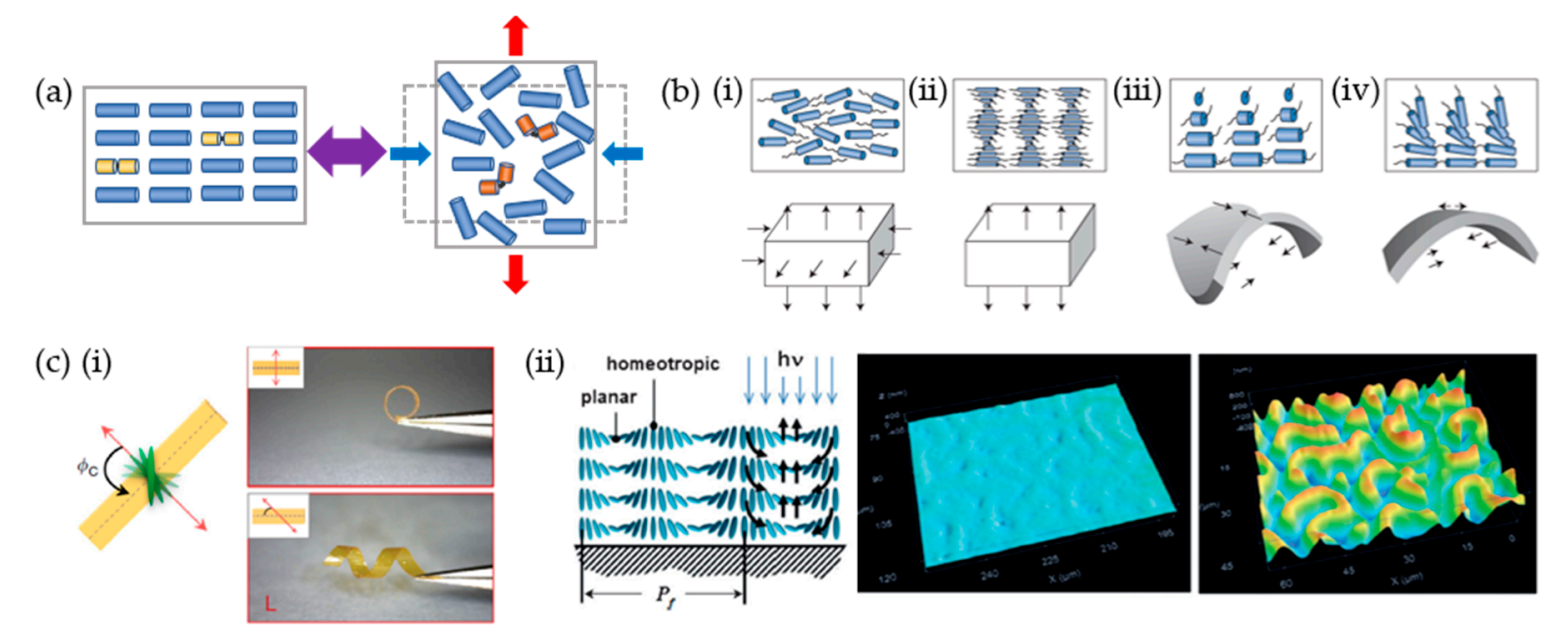

Figure 6. Principles of shape morphing for liquid crystalline polymers. (a) Schematic of the light-induced shape change of a liquid crystalline polymer resulting from the order-disorder transition. (b) Representation of the dimension changes in liquid crystalline polymers through order-disorder transition upon exposure to external stimuli: (i) uniaxial, (ii) cholesteric, (iii) twisted nematic, and (iv) hybrid geometry for liquid crystal polymers. (c) Molecular alignment-dependent actuations: (i) Bending and twisting depends on offsetting $\left(\Phi_{c}\right)$ the nematic director of the molecule at midplane (red arrow) and the cutting direction (dotted line), (ii) 3D image of a dynamic fingerprint under UV exposure with a homeotropic to planar alignment. (b) Reproduced with permission [54]. Copyright 2015, Nature Publishing Group. (c) (i) Reproduced with permission [70]. Copyright 2014, Nature Publishing Group. (ii) Reproduced with permission [71]. Copyright 2014, Nature Publishing Group.

\subsection{Walking and Crawling Motion of Liquid Crystalline Polymeric Soft Robots}

Actuation of a liquid crystalline polymeric soft robot is driven by directional contraction and expansion based on the orientation of the liquid crystalline molecules. A walking motion using the contraction and expansion between the legs is the simplest movement of a liquid crystal polymeric soft robot. Ikeda et al. demonstrated an inchworm walking motion [12] by employing alternative irradiation of UV and visible light, on a polyethylene-liquid crystalline elastomer (PE-LCE) bi-layered soft robot (Figure 7a). The PE-LCE laminated film underwent bending because of the mismatch of the coefficient of thermal expansion between the two layers. Azobenzene and the liquid crystal mesogens prepared in the smectic phase showed a higher-order along the long axis of the film. Upon UV light irradiation, soft robots expand to a flat shape and recover their initial bent shape under visible light irradiation. When the preceding principles were applied, unidirectional inchworm walking motion of the soft robot was performed by adapting the following asymmetric end shapes: flat and sharp edges on the front and back, respectively. Afterward, a monolithic liquid crystal soft robot walker, based on alternately hybrid-aligned (planar to homeotropic aligned in the thickness direction), was demonstrated by Priimagi et al. [13]. The hybrid-aligned azobenzene-doped liquid crystal bent under light irradiation because of its alignment distribution in the thickness direction. Figure $7 \mathrm{~b}$ shows three alternated hybrid-aligned segments and a $\Omega$-shaped caterpillar robot walk toward temporally modulated visible light $\left(488 \mathrm{~nm}, 150 \mathrm{~mW} \cdot \mathrm{cm}^{-2}\right)$. In addition, the alternating molecular alignment of the monolithic liquid crystalline polymer enabled soft robot crawling motion. Furthermore, Kohlmeyer et al. attempted to implement the walking motion through infrared (IR) light using carbon nanotubes (CNTs) as IR activation fillers, with LCE as the matrix/silicon bilayer (Figure 7c) [20]. Under NIR irradiation, the CNTs absorbed the light and conducted the heat to the LCE sequentially, which induced contraction by the loss of the orientational order. 

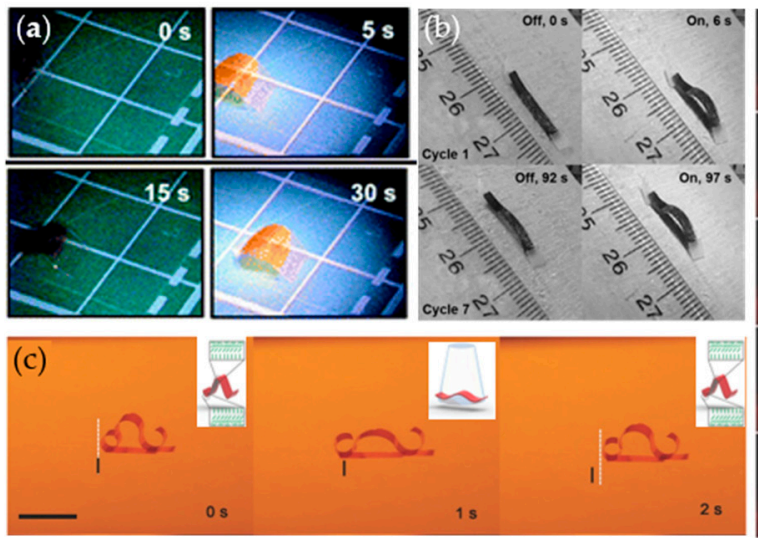
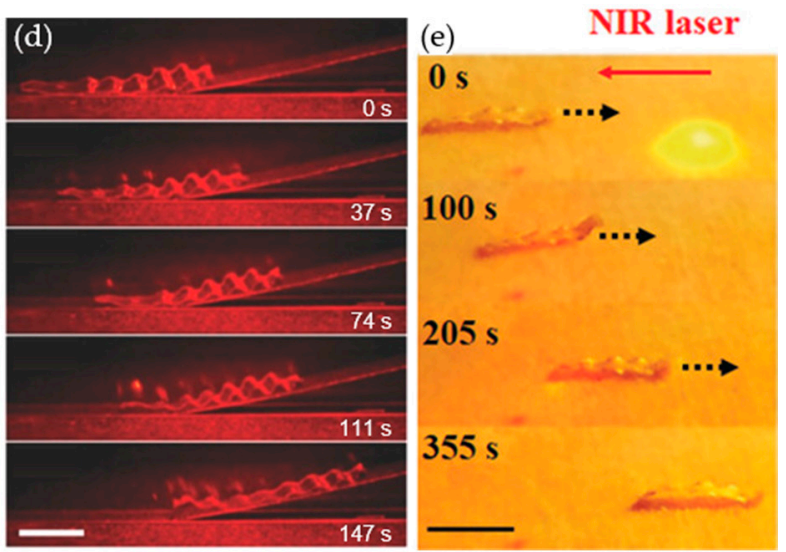

Figure 7. Crawling of liquid crystalline polymeric soft robots. (a) Photo-induced inchworm walking of the liquid crystalline polymer film by alternate irradiation with UV $\left(366 \mathrm{~nm}, 240 \mathrm{~mW} \cdot \mathrm{cm}^{-2}\right)$ and visible light $\left(>540 \mathrm{~nm}, 129 \mathrm{~mW} \cdot \mathrm{cm}^{-2}\right)$ at room temperature. (b) A light-driven caterpillar-inspired soft robot with alternated hybrid alignment (inset image). The initial bent shape deforms to flat geometry under visible light $\left(448 \mathrm{~nm}, 150 \mathrm{~mW} \cdot \mathrm{cm}^{-2}\right)$. (c) Near-infrared (NIR)-light-driven walking carbon nanotube-liquid crystalline elastomer (CNT-LCE)/silicon bilayer soft robot. (d) Climbing a hill using the crawling motion of the soft robot. (e) Crawling of the wrinkle-shaped soft robot against the laser scanning direction (NIR, $980 \mathrm{~nm}, 4.5 \mathrm{~W} \cdot \mathrm{cm}^{-2}$ ). The top of film was alternately crosslinked/decrosslinked, whereas the bottom of the film was fully decrosslinked. (a) Reproduced with permission [12]. Copyright 2009, Royal Society of Chemistry. (b) Reproduced with permission [13]. Copyright 2017, Wiley-VCH. (c) Reproduced with permission [20]. Copyright 2013, Wiley-VCH. (d) Reproduced with permission [21]. Copyright 2016, Wiley-VCH. (e) Reproduced with permission [22]. Copyright 2019, Wiley-VCH.

Crawling motions of soft robots are shown in Figure 7d,e. Wiersma and Wasylczyk demonstrated the movement of a larva-like soft robot during various tasks such as climbing a hill (Figure 7d) [21], squeezing through a slit, and moving a metal cylinder. These were accomplished by patterning the molecular orientation and through laser beam scanning. In addition, Zhao et al. employed a selective crosslinking-decrosslinking method using the anthracene moiety in LCNs (Figure 7e) [22]. Anthracene is known for reversible photodimerization $(365 \mathrm{~nm})$ and photocleavage $(254 \mathrm{~nm})$ of dimers under UV irradiation. Unidirectionally aligned anthracene functionalized LCN films can be partially decrosslinked through irradiation of a patterned $254 \mathrm{~nm}$ UV light. These decrosslinked sites can act as flexible hinges. A liquid crystalline soft robot with an alternated crosslinked-decrosslinked top surface and a fully decrosslinked bottom layer performs a crawling motion by utilizing the heat from an NIR light (Figure 7e).

\subsection{Biomimetic Swimming Motion of Liquid Crystalline Polymeric Soft Robots}

In addition to walking motions, biomimetic swimming motions at liquid-air interfaces or underwater represent an advanced field in soft robots. The swimming motion of a liquid crystal polymer was first documented by Palffy-Muhoray et al. [23]. A disk-shaped azobenzene-doped LCE swimmer was floated on ethylene glycol (Figure 8(ai)) and water (Figure 8(aii)). Photo-induced locomotion was performed using an $\mathrm{Ar}^{+}$ion laser $\left(514 \mathrm{~nm}, 1.1 \mathrm{~W} \mathrm{~cm}^{-1}\right)$. This locomotion was essentially the same in the presence of a surfactant soap. Because of the shape-morphing dependence between the molecular alignment and strain response, a polydopamine-coated LCE swimmer was reported for swimming direction control and rapid movement (Figure 8b) [24]. Polydopamine was coated on one side of the LCE film, and the LCE film was heated through the photothermal effect. Because the polydopamine has an excellent photothermal effect and strong adhesive property, a polydopamine-coated LCE swimmer is well driven on air-water surfaces. As shown in Figure 8c, Yu et al. reported an LCN-polyimide bilayer swimming robot [25], which exhibited rapid swimming motion similar to a dolphin with on-demand directional control. This was possible because the rigid LCN-based material can perform 
fast recovery as compared to that of soft LCE material. The underwater swimming motion of a soft robot is important because of its possible use in biological and medical applications. Fischer et al. demonstrated the self-propelled swimming capabilities of an LCE micro-robot in 2016 (Figure 8d) [26]. This swimming microbot had many degrees of freedom in motion because the intrabody shape change of the soft robot was controlled by structured and programmed light irradiation, providing control in terms of the pathway, speed, and location.

(a)
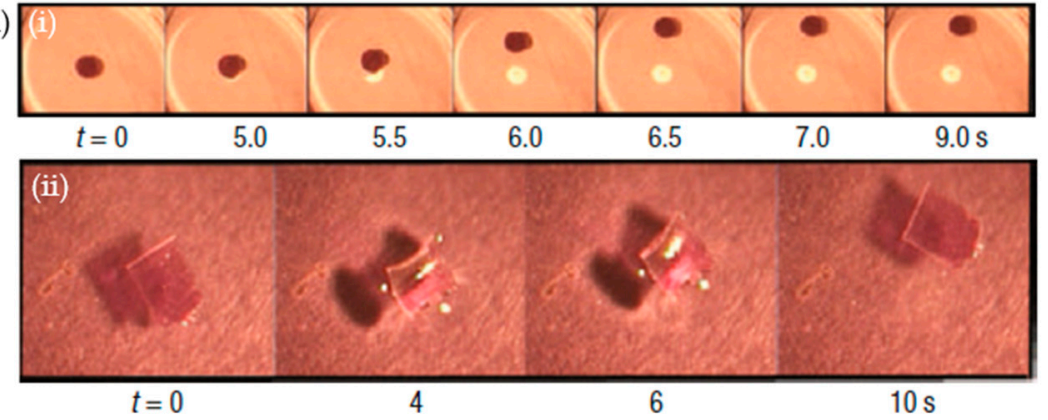

(b)
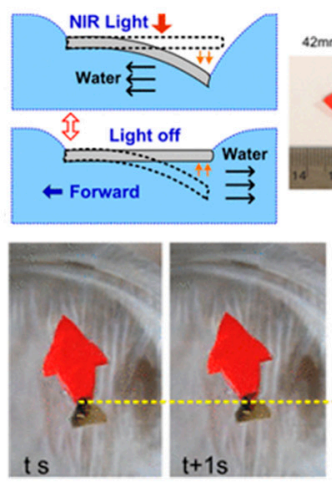
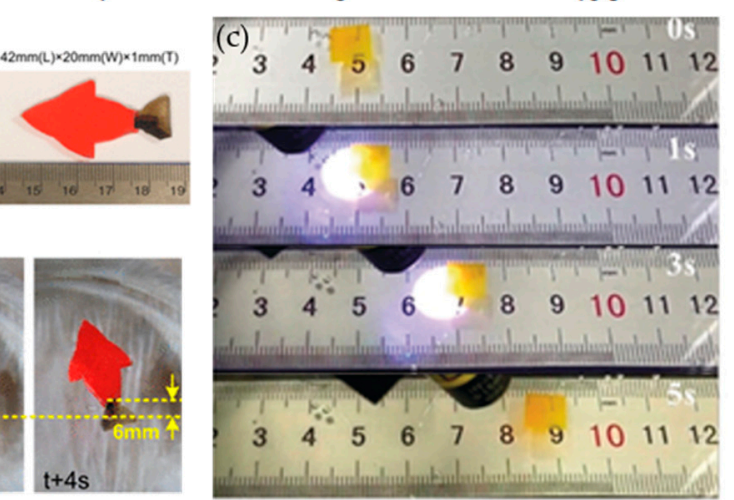

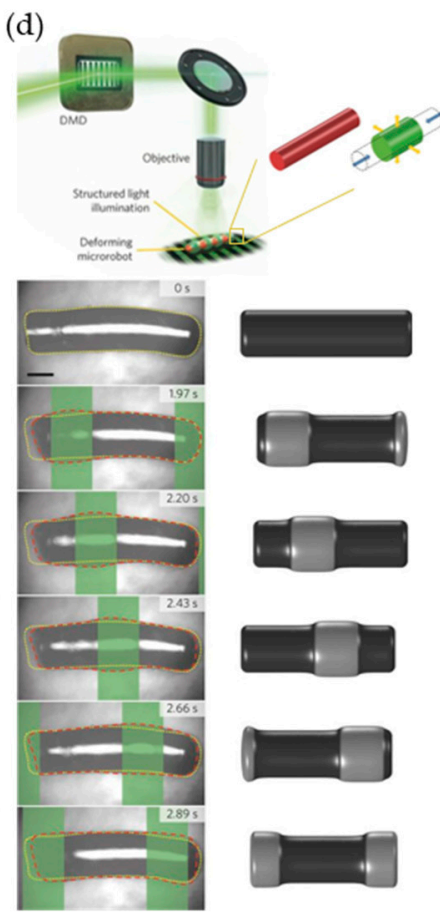

Figure 8. Swimming motion of liquid crystalline polymeric soft robots. (a) Photo-induced actuation of liquid crystal elastomer (LCE) on the liquid surface: (i) disk-shaped ( $5 \mathrm{~mm}$ in diameter, 0.32 $\mathrm{mm}$ in thickness) LCE on water swimming away from light $\left(\mathrm{Ar}^{+}\right.$ion laser, $\left.495 \mathrm{~nm}, 1.1 \mathrm{~W} \mathrm{~cm}^{-2}\right)$, (ii) rectangular-shaped LCE in ethylene glycol that folds and then swims away from the light. (b) Soft robotic swimmer based on polydopamine-coated LCE. Schematics of the bending/unbending of the soft robotic swimmer (up) and swimming motion of the soft robot near the air-water interface (down). (c) Swimming motion of an azobenzene-containing liquid crystal network (LCN)-Kapton bilayer swimmer. (d) A dynamic light field from a digital micromirror device is projected onto the liquid crystal polymeric soft robot (left), which propels itself in liquid through traveling-wave deformation (right). (a) Reproduced with permission [23]. Copyright 2004, Nature Publishing Group. (b) Reproduced with permission [24]. Copyright 2018, American Chemical Society. (c) Reproduced with permission [25]. Copyright 2019, Wiley-VCH. (d) Reproduced with permission [26]. Copyright 2016, Nature Publishing Group.

\subsection{Rolling Motion of Liquid Crystalline Polymeric Soft Robots}

Rolling is an effective in-plane locomotive mode because the rolling resistance is significantly lower than the sliding friction. The first rolling motion of a liquid crystalline polymer was demonstrated by Yamada et al. [27]. As shown in Figure 9a, an LCE ring was prepared by connecting both ends of the film. Azobenzene mesogens were aligned in a circumferential direction. Upon exposure to UV light on the underside and visible light on the upside of the ring, the LCE rolled in the irradiation direction. Rolling of a helical azo-LCN under continuous irradiation of a temporally and spatially stationary broadband UV-vis light, was demonstrated by Wie et al. (Figure 9b) [14]. When the sample was exposed to light, the upper portion of the azo-LCN film that was in the optical path attempted to adopt a greater twist in contrast to the portion in which the light was shadowed. The asymmetric 
photo-strain between the top and bottom of the helical coil induced torque to overcome the rolling resistance. In addition, broadband light also regenerated the active azobenzene molecules through cis-trans back isomerization, and the rolling persisted as long as the light irradiation continued. Another example of light-induced rolling motion was documented by Lu et al. [15]. The azobenzene liquid crystalline polymer was laminated with polypropylene and subsequently fabricated into a spring shape by twisting the film around a cylindrical rod. The motion behavior of the light-driven rolling was determined by the location of the LCE film (inside or outside): rolling away or toward the light when the LCE was outside or inside, respectively. When the ends of the helical ribbon were linked with two wheels, the rolling resistance was reduced. This enabled the soft robot to convert light into a rolling motion, more effectively (Figure 9c) [15]. Photothermal heating also generated a rolling motion in liquid crystalline materials. Ahn et al. reported the rolling motion of a CNT-LCE composite rod (Figure 9d) [16]. When the CNT-LCE rod was on a heated surface, asymmetric heat distribution, high temperature on the bottom, and low temperature on the top induced a volumetric mismatch and generated a gravitational force that caused the LCE rod to roll. Subsequently, light exposure on the CNT-LCE composite generated heat at the top portion of the rod and induced the rod's rolling motion.

(a)
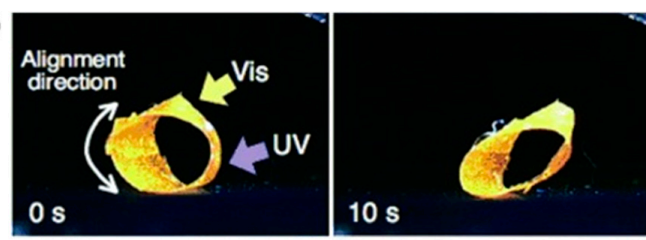

(b)
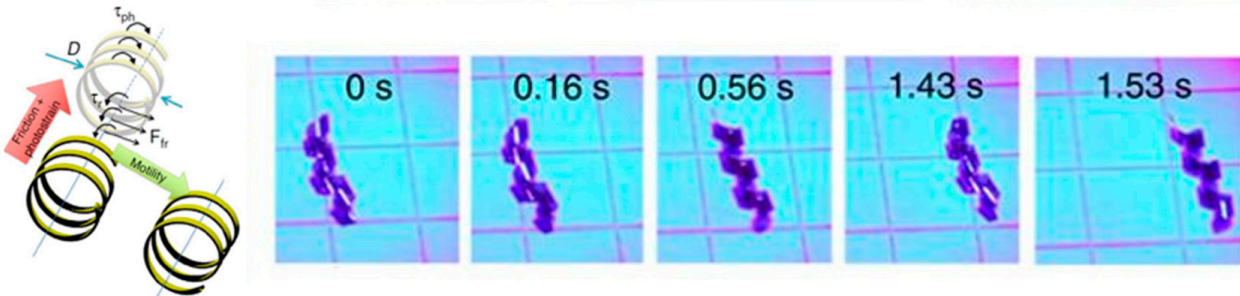

(c)
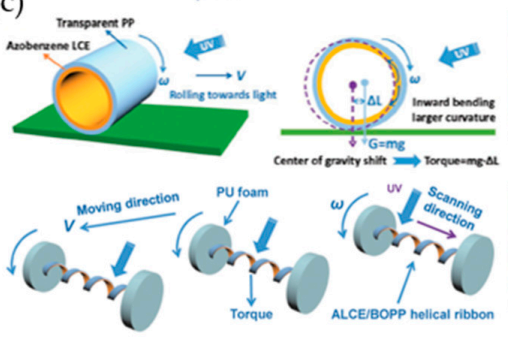

(d)
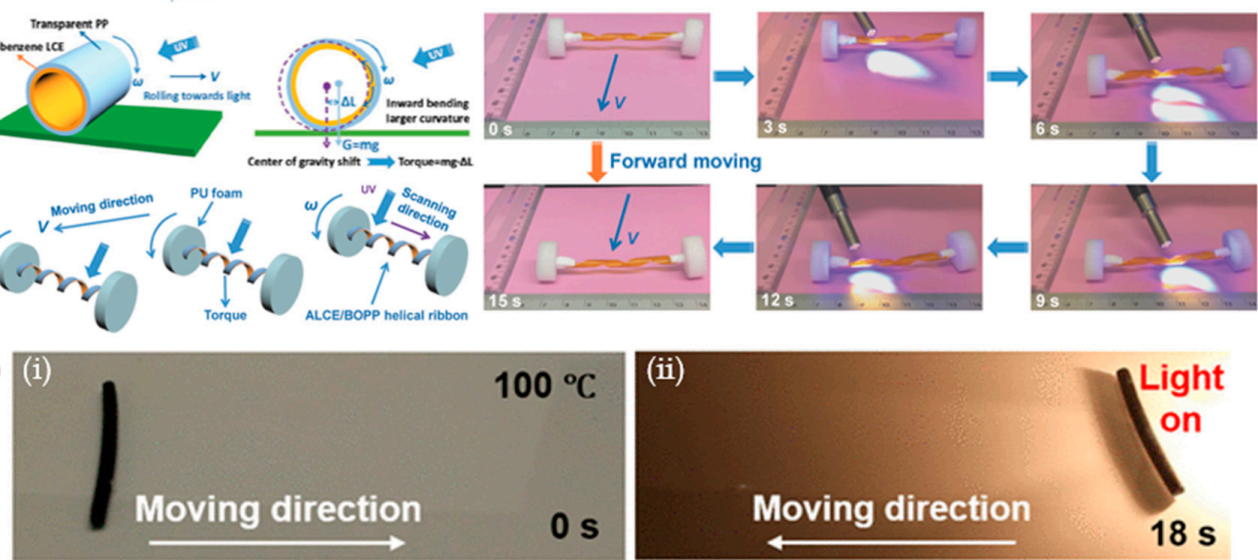

$0 \mathrm{~s}$

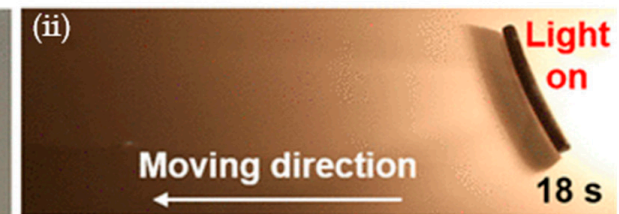

Figure 9. Rolling motions of liquid crystalline polymeric soft robots. (a) Photo-induced rolling motion of a ring-shaped LCE film. The LCE ring was irradiated through UV $\left(366 \mathrm{~nm}, 200 \mathrm{~mW} \cdot \mathrm{cm}^{-2}\right)$ and visible light ( $>500 \mathrm{~nm}, 120 \mathrm{~mW} \cdot \mathrm{cm}^{-2}$ ). (b) Rapid translation of a helical liquid crystalline polymer under continuous light illumination. (c) Light-driven forward movement of a wheel supported LCE-Polypropylene (PP) vehicle. The LCE-PP helical ribbon was configured with a spring-like motor. (d) Rolling motion of an LCE-carbon nanotube (CNT) rod: (i) rolling of the LCE-CNT rod on a hot surface, (ii) light-induced reverse rolling of an LCE-CNT composite rod on a flat hot surface. (a) Reproduced with permission [27]. Copyright 2008, Wiley-VCH. (c) Reproduced with permission [15]. Copyright 2017, Wiley-VCH. (d) Reproduced with permission [16]. Copyright 2018, American Chemical Society. 


\subsection{Wave and Jumping Motions of Liquid Crystalline Polymeric Soft Robots}

Other examples of unique motions of liquid crystalline materials were achieved by a confined structure. Gelebart et al. demonstrated the waving motion of a liquid crystal elastomeric film by confining both ends (Figure 10a) [17]. Liquid crystalline molecules and light-responsive azo molecules were aligned in a hybrid geometry-homeotropic on the surface and planar on the other. A buckled wave shape was created with the limited movements of fixed ends of the film. When irradiated by light from the side, a waving motion was initiated and repeatedly propagated. Because the azo-derivative has a very short half-life, the film can quickly recover from shadowed areas and maintain waving until the light turns off (Figure 10(ai)). Finally, LCN was attached to a non-responsive plastic frame and the photomobile device moved while the wave was traveling through the sample. The waving direction was controlled by the film orientation. Recently, a jumping motion was achieved by Ahn et al. by attaching both ends of the CNT-LCE composite film using a magnet (Figure 10b) [18]. The CNTs generated the photothermal heat on the LCE matrix under light exposure (halogen lamp, $1.57 \mathrm{~W} / \mathrm{cm}^{2}$ ) and contracted in the alignment direction. Because the magnet holds both ends of the film, energy from the photothermally generated strain was stored in the system. When light irradiation was sustained and the stored elastic energy exceeded the force of the magnet, the rapidly releasing energy was converted to a jumping motion.

(a)
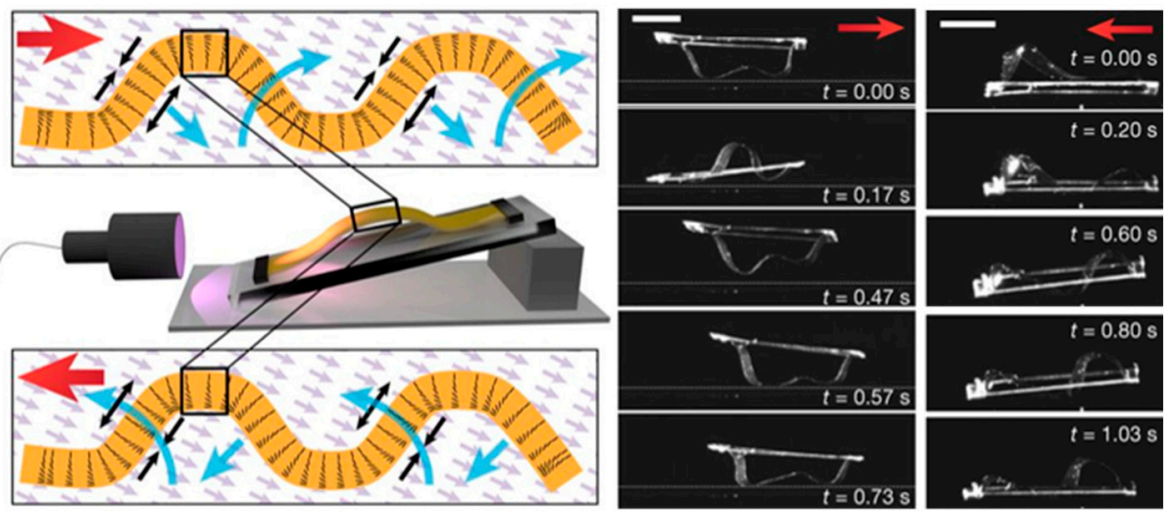

(b)

Actuating Strain

Jumping motion
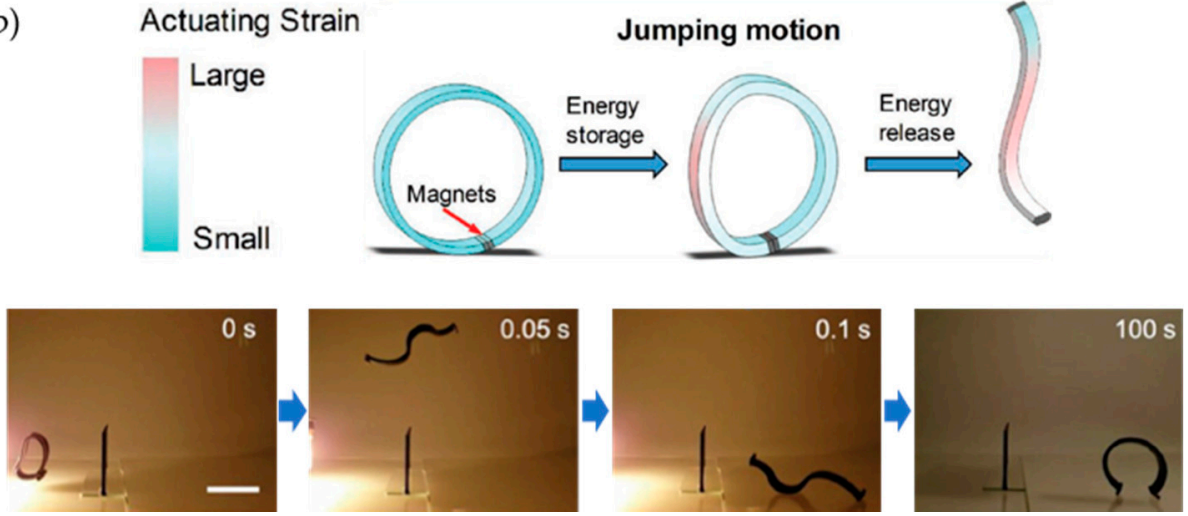

Figure 10. (a) Making waves in LCN films. (b) Jumping of CNT-LCE composites with magnets on both ends. (a) Reproduced with permission [17]. Copyright 2017, Nature Publishing Group. (b) Reproduced with permission [18]. Copyright 2019, Wiley-VCH.

\section{Hydrogel-Based Soft Robots}

Hydrogel-based soft robots are commonly manipulated by heat [29-33] and electric fields [39-42]. As previously mentioned, the volume and shape of a hydrogel can be changed when heated above the LCST, making the hydrogel a useful component in soft robots. For example, Aida et al. developed a soft robot based on an anisotropic thermal-responsive PNIPAM gel using a titanium nanosheet (TiNS) as a 
filler [28]. Gel liberated water molecules from the network and recovered their intrinsic electrostatic permittivity, thereby enhancing the electrostatic repulsion between the cofacially oriented TiNS's through heating above the LCST $\left(\sim 32^{\circ} \mathrm{C}\right)$. Enhanced electrostatic repulsion induced anisotropic thermal expansion in the orthogonal direction to the TiNS plane. As shown in Figure 11a, an L-shaped symmetric hydrogel soft robot has unidirectional procession through oscillatory change in the temperature.

(a) (i)

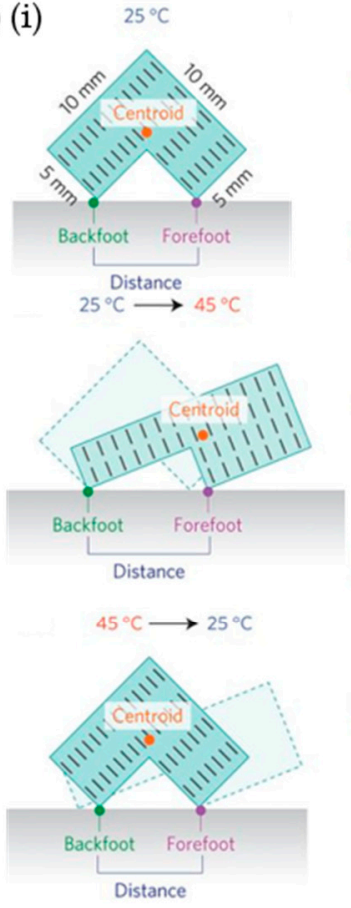

(ii)

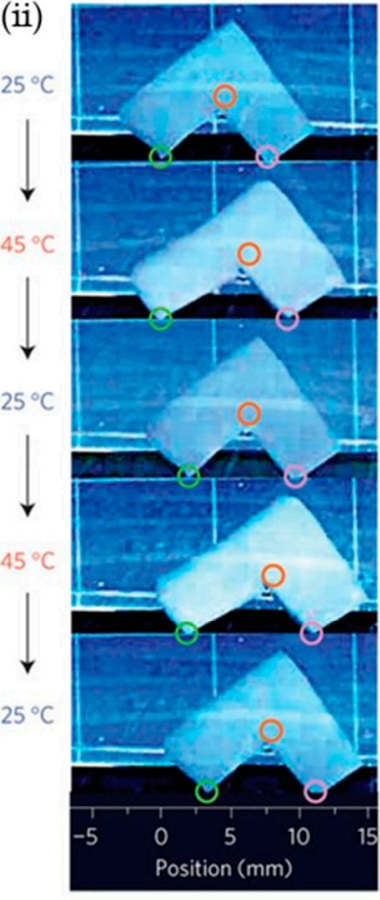

(b) (i)
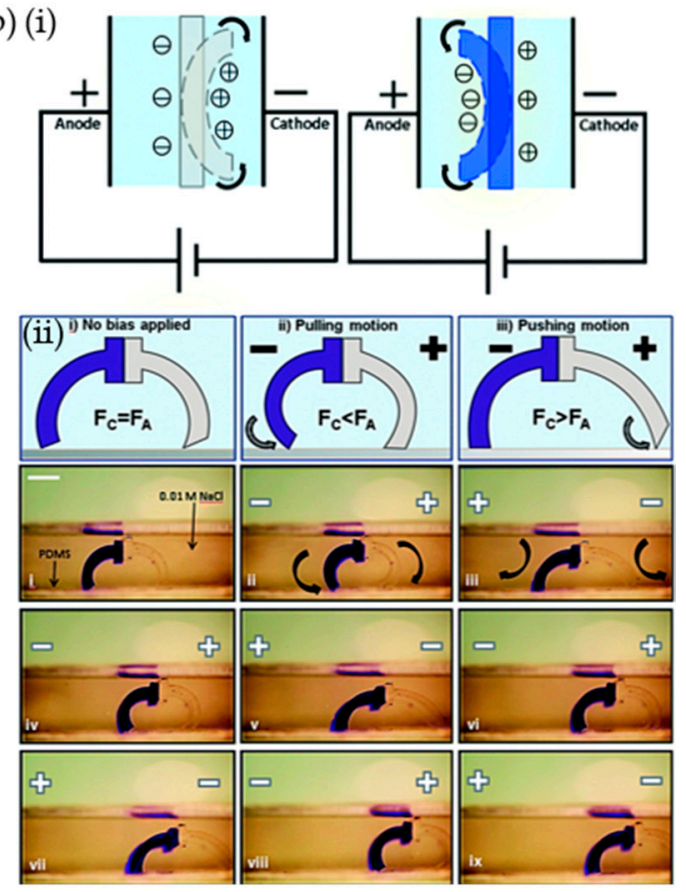

Figure 11. Actuation of hydrogel-based soft robots. (a) (i) Schematic of the ideal processing mechanism of anisotropic thermal expansion of a hydrogel-based soft robot (5 mm thick) from electrostatic repulsion of titanium nanosheet (TiNS) in dehydrated hydrogel, (ii) thermo-responsive actuation of an electrostatically anisotropic hydrogel soft robot. Alternate heating and cooling was conducted between $25{ }^{\circ} \mathrm{C}$ and $45^{\circ} \mathrm{C}$ at a rate of $0.1{ }^{\circ} \mathrm{C} / \mathrm{s}$. (b) (i) Scheme of the bending direction of electro-active materials; acrylamide (AAm)/sodium acrylated ( $\mathrm{NaAc}$ ) copolymer (light gray) and AAm/quaternized dimethylaminoethyl methacrylate (DMAEMA-Q) copolymer (blue), (ii) electro-actuated hydrogel walker in $0.01 \mathrm{M} \mathrm{NaCl}$ composed of 50\% NaAc and 30\% DMAEMA-Q legs and an applied field of 5 V/cm (scale bar: $5 \mathrm{~mm}$ ). (a) Reproduced with permission [28]. Copyright 2015, Nature Publishing Group. (b) Reproduced with permission [40]. Copyright 2014, Royal Society of Chemical.

In addition, hydrogel, which is composed of ionic materials, can be manipulated by applying electrical fields [39-42]. Electrical fields asymmetrically distribute mobile ions that create osmotic pressure differences between the ionic hydrogel and solution, which swell and deform the hydrogels. For example, Velev et al. demonstrated electro-actuated hydrogel walkers with dual responsive legs [40]. As shown in Figure 11b, they prepared two legs composed of an acrylamide (AAm)/sodium acrylated (NaAc) copolymer (shown in light gray) and AAm/quaternized dimethylaminoethyl methacrylate (DMAEMA-Q) copolymer (shown in blue), which were cationic (light gray) and anionic (blue) hydrogels. The hydrogel walker is composed of two legs which had different swelling directions that were opposite to each pole in an aqueous solution. For unidirectional continuous motion, each leg had a different tip in order to obtain an asymmetric friction coefficient, and an electric field was alternatively applied. Initially, the pole of the applied electric field coincided with the soft robot pole. This coincidence caused the legs to bend inside the soft robot. The anionic leg (light gray) had a larger contact area, with a PDMS substrate, as compared to the cationic leg (blue). This asymmetrical contact area caused the walker to move to the right. In pushing motion step, switching the field caused the anionic leg 
to stretch toward the cathode due to the higher friction force of the cationic leg, which anchored anionic leg on the substrate. Therefore, the cationic leg effectively pushed the gel walker forward. This repetitive cycle enabled the unidirectional perpetual motion of the hydrogel walker.

\section{Chemical-Based Soft Robots: Solvent and Chemical Reaction}

The actuation of solvent-responsive soft robots is driven by the swelling of polymers by solvent adsorption and deswelling of polymers by desorption under dry conditions [34-38]. For example, Aida et al. prepared a jumping soft robot based on a $\pi$-stacked carbon nitride polymer (CNP) film [37]. As shown in Figure 12a, CNP film effectively adsorbs water molecules by hydrogen bonding to unreacted nitrogen. In this state, the film has a straight form. After the water in the CNP film was removed by heating or using dry air, the film bent because of the asymmetric structure. The large and rapid actuation of the CNP film enabled jumping through the photothermal effect from irradiation with UV. In addition, Kim et al. prepared a hygroscopic responsive soft robot they called a hygrobot [38]. The hygrobot was composed of an active/inactive layer with two legs. The dry bilayer was initially bent in a convex form downward. In this configuration, the end tip of the foreleg and the knee of the back leg were in contact with the substrate. The bilayer bent upward with swelling of the active layer, and the back-leg slid to the foreleg because the static friction coefficient of the end tip was higher than that of the knee when the environmental humidity increased. When moved back to the dry condition, the foreleg slid forward given the back leg was fixed. When the humidity cycle is repeated with a temporal humidity variation, directional locomotion of the hygrobot was achieved.

(a) (i)

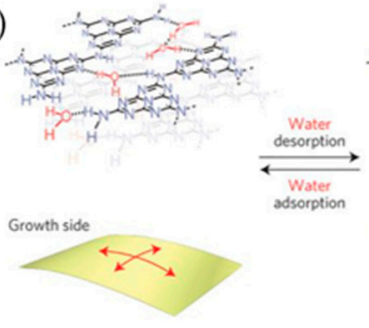

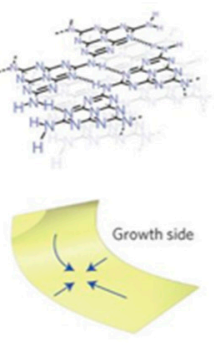

(b) (i)

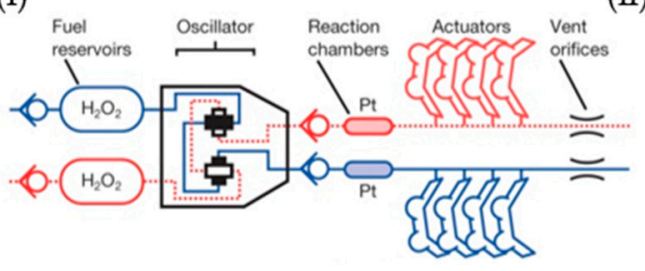

(ii)

(ii)
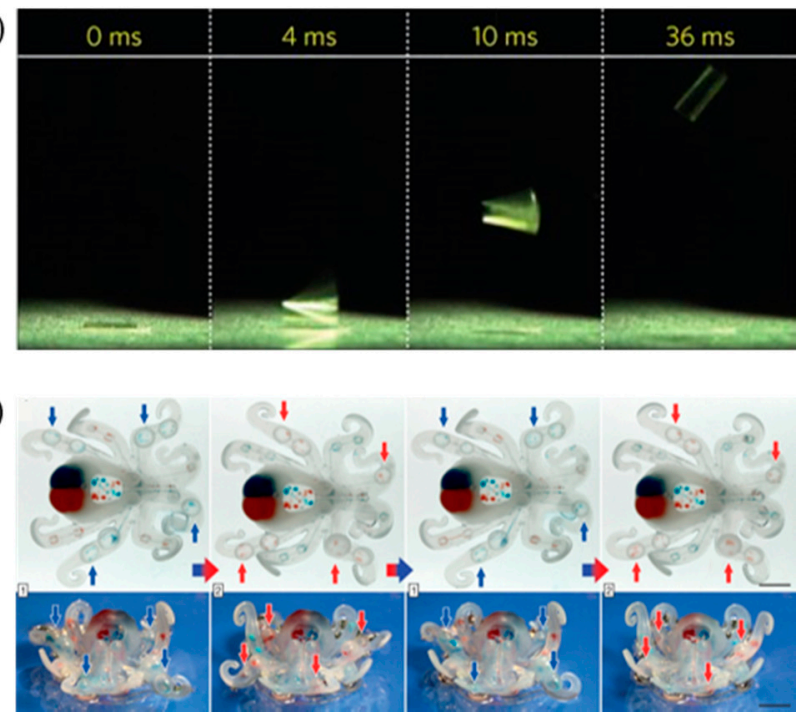

Figure 12. (a) (i) Schematic of moisture adsorption- and desorption-driven actuation of $\pi$-stacked carbon nitride polymer (CNP) film, (ii) scheme and high-speed snapshot of the jumping motion of a CNP film under UV (365 nm) irradiation. (b) (i) Scheme of the octobot system. Oxygen propellant from the decomposition of the $\mathrm{H}_{2} \mathrm{O}_{2}$ fuel induced pneumatic actuation of the octobot, (ii) monopropellant decomposition-powered actuation of the octobot (scale bar: $10 \mathrm{~mm}$ ). (a) Reproduced with permission [37]. Copyright 2016, Nature Publishing Group. (b) Reproduced with permission [43]. Copyright 2016, Nature Publishing Group.

Pneumatic soft robots have successfully demonstrated various actuation modes such as crawlers [77,78], swimmers [79], and robust jumpers [80,81]. However, a rigid power supply and controller are tethered to the soft robots or on-board systems are used to control the aforementioned soft robots. To create fully soft and autonomous robots, Wood et al. developed an octopus-shaped autonomous pneumatic soft robot by implementing chemical decomposition of monopropellant fuels (Figure 12b) [43]. A microfluidic soft controller was embedded in the octopus-shaped soft robot, 
called an octobot, to supply pressure to the legs. The flow of fuel (hydrogen peroxide $\left(\mathrm{H}_{2} \mathrm{O}_{2}\right)$ ) was controlled by an oscillator that included a check valve to reach the reaction chamber. During this stage, the gas pressurized the microfluidic channel and deformed the legs from chemical deposition of the liquid fuel.

\section{Outlook and Conclusions}

In this review, we highlighted the recent examples of polymeric materials for untethered soft robots such as magnetic composites, light-responsive liquid crystalline materials, and various polymeric materials responsive to heat, solvents, and gases formed by chemical reactions. Two major themes were identified in the soft robotics research: diversification of soft robots in terms of motions and stimuli. Assorted movements such as rolling, jumping, and swimming were achieved by programming magnet particles within composites and molecular orientation of liquid crystalline materials. Examples of variegated stimuli included the study of temperature-induced walking motion with hydrogels containing titanium nanosheets, which generate anisotropic thermal expansion and electro-activity of dual responsive anionic and cationic hydrogels that respond to positive or negative charge. Other examples included CNP film jumping, hygrobot walking using moisture adsorption-desorption, and an octobot that uses pneumatic pressure generated by the decomposition of $\mathrm{H}_{2} \mathrm{O}_{2}$. Each method has advantages and disadvantages. For example, in the case of photoactive robots, the light propagation pathway to the robot should be secured. Magnetomotility was shown to have a distance limitation in terms of the controllable range because the magnetic field is considerably dependent on the distance from the source. In addition, creating a uniform magnetic field over a large area was found to be difficult. For solvent or water-driven systems, wet operating conditions hinder precise actuation control such as spatiotemporally-localized actuation or controlled magnitude of actuation. Ultimately, multi-responsive soft robotic systems are necessary to circumvent the limitations of stimuli and materials.

The ideal goal of a soft robot is to perform a variety of sophisticated movements with a large magnitude of both stress and strain responses, under simple external stimuli. In general, however, sophisticated and programmed external stimuli are required to manipulate soft robots consisting of isotropic materials. Conversely, programmable anisotropic materials enable soft robots to be easily regulated through simple stimulation. Even for programmable anisotropic materials, simple stimulation often results in the repetition of single-mode motility. Therefore, the combination of programmable materials and stimuli is essential to achieve wireless controlled soft robots capable of multi-modal locomotion, as exemplified by the recent report from Sitti et al. [9]. In addition to multi-modal motility under external stimuli, generating large stress is necessary to perform various functions. Simultaneous generation of large stress and strain responses is often limited by stress-strain correlations [82,83]. A good example of achieving both large strain and stress response is liquid crystal elastomers, which can lift 2700 times their weight through cooperative motions, as reported by White et al. [84]. For further research trends, soft robots will be able to achieve various motions by discrete stimuli in terms of multimodal actuations. The anisotropic factors of geometrical shape, material alignment, and material polarity play pivotal roles in regulating multifunctional soft robots. In addition, multi-stimuli response is needed to push the limits of one system to other stimuli. For example, if a soft robot can independently react to all orthogonal stimuli, one robot can have complex motions with multi-stimuli input, such as holding an object by light while spatially moving under a magnetic field. Furthermore, a motion tracking system will help complete complex movements of soft robot by providing instant feedback on the localized stimuli based on real-time positional information. Finally, we expect that the integrated motion-tracking and stimuli localization will be further refined through machine learning.

Author Contributions: Author Contributions: J.J.W. directed the project. J.G.K., J.E.P., S.W., J.J., J.J.W. wrote the paper. All Authors provided feedback and helped shape the article.

Funding: This research was funded by Inha University 58410-1. 
Conflicts of Interest: The authors declare no conflict of interest.

\section{References}

1. Tottori, S.; Zhang, L.; Qiu, F.; Krawczyk, K.K.; Franco-Obregón, A.; Nelson, B.J. Magnetic helical micromachines: fabrication, controlled swimming, and cargo transport. Adv. Mater. 2012, 24, 811-816. [CrossRef] [PubMed]

2. Yan, X.; Zhou, Q.; Vincent, M.; Deng, Y.; Yu, J.; Xu, J.; Xu, T.; Tang, T.; Bian, L.; Wang, Y.-X.J.; et al. Multifunctional biohybrid magnetite microrobots for imaging-guided therapy. Sci. Robot. 2017, 2, eaaq1155. [CrossRef]

3. Zhang, L.; Abbott, J.J.; Dong, L.; Peyer, K.E.; Kratochvil, B.E.; Zhang, H.; Bergeles, C.; Nelson, B.J. Characterizing the swimming properties of artificial bacterial flagella. Nano Lett. 2009, 9, 3663-3667. [CrossRef] [PubMed]

4. Huang, H.-W.; Sakar, M.S.; Petruska, A.J.; Pané, S.; Nelson, B.J. Soft micromachines with programmable motility and morphology. Nat. Commun. 2016, 7, 12263. [CrossRef] [PubMed]

5. Kim, J.; Chung, S.E.; Choi, S.-E.; Lee, H.; Kim, J.; Kwon, S. Programming magnetic anisotropy in polymeric microactuators. Nat. Mater. 2011, 10, 747. [CrossRef] [PubMed]

6. Lu, H.; Zhang, M.; Yang, Y.; Huang, Q.; Fukuda, T.; Wang, Z.; Shen, Y. A bioinspired multilegged soft millirobot that functions in both dry and wet conditions. Nat. Commun. 2018, 9, 3944. [CrossRef] [PubMed]

7. Park, J.E.; Jeon, J.; Cho, J.H.; Won, S.; Jin, H.-J.; Lee, K.H.; Wie, J.J. Magnetomotility of untethered helical soft robots. RSC Adv. 2019, 9, 11272-11280. [CrossRef]

8. Bi, C.; Guix, M.; Johnson, V.B.; Jing, W.; Cappelleri, J.D. Design of microscale magnetic tumbling robots for locomotion in multiple environments and complex terrains. Micromachines 2018, 9, 68. [CrossRef] [PubMed]

9. Hu, W.; Lum, G.Z.; Mastrangeli, M.; Sitti, M. Small-scale soft-bodied robot with multimodal locomotion. Nature 2018, 554, 81-85. [CrossRef]

10. Kim, Y.; Yuk, H.; Zhao, R.; Chester, S.A.; Zhao, X. Printing ferromagnetic domains for untethered fast-Transforming soft materials. Nature 2018, 558, 274-279. [CrossRef]

11. Zhang, L.; Abbott, J.J.; Dong, L.; Kratochvil, B.E.; Bell, D.; Nelson, B.J. Artificial bacterial flagella: Fabrication and magnetic control. Appl. Phys. Lett. 2009, 94, 064107. [CrossRef]

12. Yamada, M.; Kondo, M.; Miyasato, R.; Naka, Y.; Mamiya, J.I.; Kinoshita, M.; Shishido, A.; Yu, Y.; Barrett, C.J.; Ikeda, T. Photomobile polymer materials—various three-dimensional movements. J. Mater. Chem. 2009, 19, 60-62. [CrossRef]

13. Zeng, H.; Wani, O.M.; Wasylczyk, P.; Priimagi, A. Light-driven, caterpillar-inspired miniature inching robot. Macromol. Rapid Commun. 2018, 39, 1700224. [CrossRef] [PubMed]

14. Wie, J.J.; Shankar, M.R.; White, T.J. Photomotility of polymers. Nat. Commun. 2016, 7, 13260. [CrossRef] [PubMed]

15. Lu, X.; Guo, S.; Tong, X.; Xia, H.; Zhao, Y. Tunable photocontrolled motions using stored strain energy in malleable azobenzene liquid crystalline polymer actuators. Adv. Mater. 2017, 29, 1606467. [CrossRef] [PubMed]

16. Ahn, C.; Li, K.; Cai, S. Light or thermally powered autonomous rolling of an elastomer rod. ACS Appl. Mater. Interfaces 2018, 10, 25689-25696. [CrossRef] [PubMed]

17. Gelebart, A.H.; Jan Mulder, D.; Varga, M.; Konya, A.; Vantomme, G.; Meijer, E.W.; Selinger, R.L.B.; Broer, D.J. Making waves in a photoactive polymer film. Nature 2017, 546, 632-636. [CrossRef] [PubMed]

18. Ahn, C.; Liang, X.; Cai, S. Bioinspired design of light-powered crawling, squeezing, and jumping untethered soft robot. Adv. Mater. Technol. 2019, 4, 1900185. [CrossRef]

19. Zeng, H.; Wasylczyk, P.; Parmeggiani, C.; Martella, D.; Burresi, M.; Wiersma, D.S. Light-fueled microscopic walkers. Adv. Mater. 2015, 27, 3883-3887. [CrossRef]

20. Kohlmeyer, R.R.; Chen, J. Wavelength-selective, IR light-driven hinges based on liquid crystalline elastomer composites. Angew. Chem. Int. Ed. 2013, 52, 9234-9237. [CrossRef]

21. Rogóż, M.; Zeng, H.; Xuan, C.; Wiersma, D.S.; Wasylczyk, P. Light-driven soft robot mimics caterpillar locomotion in natural scale. Adv. Opt. Mater. 2016, 4, 1689-1694. [CrossRef] 
22. Jiang, Z.C.; Xiao, Y.Y.; Tong, X.; Zhao, Y. Selective decrosslinking in liquid crystal polymer actuators for optical reconfiguration of origami and light-fueled locomotion. Angew. Chem. Int. Ed. 2019, 58, 5332-5337. [CrossRef] [PubMed]

23. Camacho-Lopez, M.; Finkelmann, H.; Palffy-Muhoray, P.; Shelley, M. Fast liquid-crystal elastomer swims into the dark. Nat. Mater. 2004, 3, 307-310. [CrossRef] [PubMed]

24. Tian, H.; Wang, Z.; Chen, Y.; Shao, J.; Gao, T.; Cai, S. Polydopamine-coated main-chain liquid crystal elastomer as optically driven artificial muscle. ACS Appl. Mater. Interfaces 2018, 10, 8307-8316. [CrossRef] [PubMed]

25. Ma, S.; Li, X.; Huang, S.; Hu, J.; Yu, H. A Light-activated polymer composite enables on-demand photocontrolled motion: transportation at the liquid/air interface. Angew. Chem. Int. Ed. 2019, 58, 2655-2659. [CrossRef] [PubMed]

26. Palagi, S.; Mark, A.G.; Reigh, S.Y.; Melde, K.; Qiu, T.; Zeng, H.; Parmeggiani, C.; Martella, D.; Sanchez-Castillo, A.; Kapernaum, N.; et al. Structured light enables biomimetic swimming and versatile locomotion of photoresponsive soft microrobots. Nat. Mater. 2016, 15, 647-653. [CrossRef] [PubMed]

27. Yamada, M.; Kondo, M.; Mamiya, J.I.; Yu, Y.; Kinoshita, M.; Barrett, C.J.; Ikeda, T. Photomobile polymer materials: towards light-driven plastic motors. Angew. Chem. Int. Ed. 2008, 47, 4986-4988. [CrossRef] [PubMed]

28. Sydney Gladman, A.; Matsumoto, E.A.; Nuzzo, R.G.; Mahadevan, L.; Lewis, J.A. Biomimetic 4D printing. Nat. Mater. 2016, 15, 413. [CrossRef] [PubMed]

29. Kim, Y.S.; Liu, M.; Ishida, Y.; Ebina, Y.; Osada, M.; Sasaki, T.; Hikima, T.; Takata, M.; Aida, T. Thermoresponsive actuation enabled by permittivity switching in an electrostatically anisotropic hydrogel. Nat. Mater. 2015, 14, 1002-1007. [CrossRef] [PubMed]

30. Wang, E.; Desai, M.S.; Lee, S.W. Light-controlled graphene-elastin composite hydrogel actuators. Nano Lett. 2013, 13, 2826-2830. [CrossRef] [PubMed]

31. Gao, G.; Wang, Z.; Xu, D.; Wang, L.; Xu, T.; Zhang, H.; Chen, J.; Fu, J. Snap-buckling motivated controllable jumping of thermo-responsive hydrogel bilayers. ACS Appl. Mater. Interfaces 2018, 10, 41724-41731. [CrossRef] [PubMed]

32. Luo, R.; Wu, J.; Dinh, N.D.; Chen, C.H. Gradient porous elastic hydrogels with shape-memory property and anisotropic responses for programmable locomotion. Adv. Funct. Mater. 2015, 25, 7272-7279. [CrossRef]

33. Sun, Z.; Yamauchi, Y.; Araoka, F.; Kim, Y.S.; Bergueiro, J.; Ishida, Y.; Ebina, Y.; Sasaki, T.; Hikima, T.; Aida, T. An anisotropic hydrogel actuator enabling earthworm-like directed peristaltic crawling. Angew. Chem. Int. Ed. 2018, 57, 15772-15776. [CrossRef] [PubMed]

34. Lee, H.; Xia, C.; Fang, N.X. First jump of microgel; actuation speed enhancement by elastic instability. Soft Matter 2010, 6, 4342-4345. [CrossRef]

35. Ma, Y.; Zhang, Y.; Wu, B.; Sun, W.; Li, Z.; Sun, J. Polyelectrolyte multilayer films for building energetic walking devices. Angew. Chem. Int. Ed. 2011, 50, 6254-6257. [CrossRef] [PubMed]

36. Hore, D.; Majumder, A.; Mondal, S.; Roy, A.; Ghatak, A. How to make a cylinder roll uphill. Soft Matter 2012, 8, 5038-5042. [CrossRef]

37. Arazoe, H.; Miyajima, D.; Akaike, K.; Araoka, F.; Sato, E.; Hikima, T.; Kawamoto, M.; Aida, T. An autonomous actuator driven by fluctuations in ambient humidity. Nat. Mater. 2016, 15, 1084. [CrossRef] [PubMed]

38. Shin, B.; Ha, J.; Lee, M.; Park, K.; Park, G.H.; Choi, T.H.; Cho, K.-J.; Kim, H.-Y. Hygrobot: A self-locomotive ratcheted actuator powered by environmental humidity. Sci. Robot. 2018, 3, eaar2629. [CrossRef]

39. Kwon, G.H.; Park, J.Y.; Kim, J.Y.; Frisk, M.L.; Beebe, D.J.; Lee, S.-H. Biomimetic soft multifunctional miniature aquabots. Small 2008, 4, 2148-2153. [CrossRef]

40. Morales, D.; Palleau, E.; Dickey, M.D.; Velev, O.D. Electro-actuated hydrogel walkers with dual responsive legs. Soft Matter 2014, 10, 1337-1348. [CrossRef]

41. Yang, C.; Wang, W.; Yao, C.; Xie, R.; Ju, X.J.; Liu, Z.; Chu, L.Y. Hydrogel walkers with electro-driven motility for cargo transport. Sci. Rep. 2015, 5, 13622. [CrossRef] [PubMed]

42. Han, D.; Farino, C.; Yang, C.; Scott, T.; Browe, D.; Choi, W.; Freeman, J.W.; Lee, H. Soft robotic manipulation and locomotion with a 3D printed electroactive hydrogel. ACS Appl. Mater. Interfaces 2018, 10, 17512-17518. [CrossRef] [PubMed]

43. Wehner, M.; Truby, R.L.; Fitzgerald, D.J.; Mosadegh, B.; Whitesides, G.M.; Lewis, J.A.; Wood, R.J. An integrated design and fabrication strategy for entirely soft, autonomous robots. Nature 2016, 536, 451-455. [CrossRef] [PubMed] 
44. Zolfagharian, A.; Kaynak, A.; Khoo, S.Y.; Zhang, J.; Nahavandi, S.; Kouzani, A. Control-oriented modelling of a 3D-printed soft actuator. Materials 2019, 12, 71. [CrossRef] [PubMed]

45. Zolfagharian, A.; Kouzani, A.; Khoo, S.Y.; Nasri-Nasrabadi, B.; Kaynak, A. Development and analysis of a 3D printed hydrogel soft actuator. Sens. Actuators A Phys 2017, 265, 94-101. [CrossRef]

46. Zolfagharian, A.; Kouzani, A.; Moghadam, A.; Khoo, S.Y.; Nahavandi, S.; Kaynak, A. Rigid elements dynamics modeling of a 3D printed soft actuator. Smart Mater. Struct. 2019, 28, 025003. [CrossRef]

47. Lancia, F.; Ryabchun, A.; Katsonis, N. Life-like motion driven by artificial molecular machines. Nat. Rev. Chem. 2019, 1-16, 536-551. [CrossRef]

48. Boelke, J.; Hecht, S. Designing molecular photoswitches for soft materials applications. Adv. Opt. Mater. 2019, 7. [CrossRef]

49. Laschi, C.; Mazzolai, B.; Cianchetti, M. Soft robotics: technologies and systems pushing the boundaries of robot abilities. Sci. Robot. 2016, 1, eaah3690. [CrossRef]

50. Jiang, Z.C.; Xiao, Y.Y.; Zhao, Y. Shining light on liquid crystal polymer networks: Preparing, reconfiguring, and driving soft actuators. Adv. Opt. Mater. 2019, 7. [CrossRef]

51. Kageyama, Y. Light-powered self-sustainable macroscopic motion for the active locomotion of materials. ChemPhotoChem 2019, 3, 327-336. [CrossRef]

52. Zeng, H.; Wasylczyk, P.; Wiersma, D.S.; Priimagi, A. Light robots: bridging the gap between microrobotics and photomechanics in soft materials. Adv. Mater. 2018, 30. [CrossRef] [PubMed]

53. Hines, L.; Petersen, K.; Lum, G.Z.; Sitti, M. Soft actuators for small-scale robotics. Adv. Mater. 2017, $29,1603483$. [CrossRef] [PubMed]

54. White, T.J.; Broer, D.J. Programmable and adaptive mechanics with liquid crystal polymer networks and elastomers. Nat. Mater. 2015, 14, 1087-1098. [CrossRef] [PubMed]

55. Aubin, C.A.; Choudhury, S.; Jerch, R.; Archer, L.A.; Pikul, J.H.; Shepherd, R.F. Electrolytic vascular systems for energy-dense robots. Nature 2019, 571, 51-57. [CrossRef] [PubMed]

56. Ilievski, F.; Mazzeo, A.D.; Shepherd, R.F.; Chen, X.; Whitesides, G.M. Soft robotics for chemists. Angew. Chem. Int. Ed. 2011, 50, 1890-1895. [CrossRef] [PubMed]

57. Wang, X.; Qin, X.H.; Hu, C.; Terzopoulou, A.; Chen, X.Z.; Huang, T.Y.; Maniura-Weber, K.; Pané, S.; Nelson, B.J. 3D printed enzymatically biodegradable soft helical microswimmers. Adv. Funct. Mater. 2018, 28, 1804107. [CrossRef]

58. Tumanski, S. Handbook of Magnetic Measurements, 1st ed.; CRC Press: Boca Raton, FL, USA, 2016; ISBN 978-1439829516.

59. Sung Lee, J.; Myung Cha, J.; Young Yoon, H.; Lee, J.-K.; Keun Kim, Y. Magnetic multi-granule nanoclusters: A model system that exhibits universal size effect of magnetic coercivity. Sci. Rep. 2015, 5, 12135. [CrossRef]

60. Zeng, Q.; Jiang, D.; Yang, S. Enhancement of magnetic properties in hard/soft $\mathrm{CoFe}{ }_{2} \mathrm{O}_{4} / \mathrm{Fe}_{3} \mathrm{O}_{4}$ nanocomposites. RSC Adv. 2016, 6, 46143-46148. [CrossRef]

61. Fei, C.; Zhang, Y.; Yang, Z.; Liu, Y.; Xiong, R.; Shi, J.; Ruan, X. Synthesis and magnetic properties of hard magnetic $\left(\mathrm{CoFe}_{2} \mathrm{O}_{4}\right)$-soft magnetic $\left(\mathrm{Fe}_{3} \mathrm{O}_{4}\right)$ nano-composite ceramics by SPS technology. J. Magn. Magn. Mater. 2011, 323, 1811-1816. [CrossRef]

62. Victora, R.H.; Shen, X. Composite media for perpendicular magnetic recording. IEEE Trans. Magn. 2005, 41, 537-542. [CrossRef]

63. Davies, J.E.; Hellwig, O.; Fullerton, E.E.; Jiang, J.S.; Bader, S.D.; Zimányi, G.T.; Liu, K. Anisotropy dependence of irreversible switching in $\mathrm{Fe} / \mathrm{SmCo}$ and $\mathrm{FeNi} / \mathrm{FePt}$ exchange spring magnet films. Appl. Phys. Lett. 2005, 86, 262503. [CrossRef]

64. Ullah, Z.; Atiq, S.; Naseem, S. Influence of Pb doping on structural, electrical and magnetic properties of Sr-hexaferrites. J. Alloys Compd. 2013, 555, 263-267. [CrossRef]

65. Liu, X.M.; Wang, L.S.; Wang, L.; Huang, J.; He, C. The effect of salt and pH on the phase-transition behaviors of temperature-sensitive copolymers based on N-isopropylacrylamide. Biomaterials 2004, 25, 5659-5666. [CrossRef] [PubMed]

66. Jánossy, I.; Lloyd, A.D.; Wherrett, B.S. Anomalous optical freedericksz transition in an absorbing liquid crystal. Mol. Cryst. Liq. Cryst. Inc. Nonlinear Opt. 1990, 179, 1-12. [CrossRef]

67. Wermter, H.; Finkelmann, H. Liquid crystalline elastomers as artificial muscles. E-Polymers 2001. [CrossRef]

68. Ware, T.H.; McConney, M.E.; Wie, J.J.; Tondiglia, V.P.; White, T.J. Voxelated liquid crystal elastomers. Science 2015, 347, 982-984. [CrossRef] [PubMed] 
69. Disch, S.; Schmidt, C.; Finkelmann, H. Nematic elastomers beyond the critical point. Macromol. Rapid Commun. 1994, 15, 303-310. [CrossRef]

70. Iamsaard, S.; Aßhoff, S.J.; Matt, B.; Kudernac, T.; Cornelissen, J.J.L.M.; Fletcher, S.P.; Katsonis, N. Conversion of light into macroscopic helical motion. Nat. Chem. 2014, 6, 229. [CrossRef]

71. Liu, D.; Broer, D.J. Self-assembled dynamic 3D fingerprints in liquid-crystal coatings towards controllable friction and adhesion. Angew. Chem. Int. Ed. 2014, 53, 4542-4546. [CrossRef]

72. Kotikian, A.; Truby, R.L.; Boley, J.W.; White, T.J.; Lewis, J.A. 3D printing of liquid crystal elastomeric actuators with spatially programed nematic order. Adv. Mater. 2018, 30, 1706164. [CrossRef] [PubMed]

73. Ambulo, C.P.; Burroughs, J.J.; Boothby, J.M.; Kim, H.; Shankar, M.R.; Ware, T.H. Four-dimensional printing of liquid crystal elastomers. ACS Appl. Mater. Interfaces 2017, 9, 37332-37339. [CrossRef] [PubMed]

74. Saed, M.O.; Ambulo, C.P.; Kim, H.; De, R.; Raval, V.; Searles, K.; Siddiqui, D.A.; Cue, J.M.O.; Stefan, M.C.; Shankar, M.R.; et al. Molecularly-engineered, 4D-printed liquid crystal elastomer actuators. Adv. Funct. Mater. 2019, 29, 1806412. [CrossRef]

75. Zeng, H.; Wasylczyk, P.; Cerretti, G.; Martella, D.; Parmeggiani, C.; Wiersma, D.S. Alignment engineering in liquid crystalline elastomers: Free-form microstructures with multiple functionalities. Appl. Phys. Lett. 2015, 106, 111902. [CrossRef]

76. Akdeniz, B.; Bukusoglu, E. Liquid crystal templates combined with photolithography enable synthesis of chiral twisted polymeric microparticles. Macromol. Rapid Commun. 2019, 40. [CrossRef]

77. Shepherd, R.F.; Ilievski, F.; Choi, W.; Morin, S.A.; Stokes, A.A.; Mazzeo, A.D.; Chen, X.; Wang, M.; Whitesides, G.M. Multigait soft robot. Proc. Natl. Acad. Sci. USA 2011, 108, 20400-20403. [CrossRef] [PubMed]

78. Tolley, M.T.; Shepherd, R.F.; Mosadegh, B.; Galloway, K.C.; Wehner, M.; Karpelson, M.; Wood, R.J.; Whitesides, G.M. A Resilient, Untethered soft robot. Soft Robot. 2014, 1, 213-223. [CrossRef]

79. Marchese, A.D.; Onal, C.D.; Rus, D. Autonomous soft robotic fish capable of escape maneuvers using fluidic elastomer actuators. Soft Robot. 2014, 1, 75-87. [CrossRef]

80. Shepherd, R.F.; Stokes, A.A.; Freake, J.; Barber, J.; Snyder, P.W.; Mazzeo, A.D.; Cademartiri, L.; Morin, S.A.; Whitesides, G.M. Using explosions to power a soft robot. Angew. Chem. Int. Ed. 2013, 52, 2892-2896. [CrossRef]

81. Bartlett, N.W.; Tolley, M.T.; Overvelde, J.T.B.; Weaver, J.C.; Mosadegh, B.; Bertoldi, K.; Whitesides, G.M.; Wood, R.J. A 3D-printed, functionally graded soft robot powered by combustion. Science 2015, 349, 161-165. [CrossRef]

82. Wang, D.H.; Wie, J.J.; Lee, K.M.; White, T.J.; Tan, L.-S. Impact of backbone rigidity on the photomechanical response of glassy, azobenzene-functionalized polyimides. Macromolecules 2014, 47, 659-667. [CrossRef]

83. Wie, J.J.; Wang, D.H.; Lee, K.M.; Tan, L.S.; White, T.J. Molecular engineering of azobenzene-functionalized polyimides to enhance both photomechanical work and motion. Chem. Mater. 2014, 26, 5223-5230. [CrossRef]

84. Guin, T.; Settle, M.J.; Kowalski, B.A.; Auguste, A.D.; Beblo, R.V.; Reich, G.W.; White, T.J. Layered liquid crystal elastomer actuators. Nat. Commun. 2018, 9, 2531. [CrossRef]

(C) 2019 by the authors. Licensee MDPI, Basel, Switzerland. This article is an open access article distributed under the terms and conditions of the Creative Commons Attribution (CC BY) license (http://creativecommons.org/licenses/by/4.0/). 